RESEARCH ARTICLE SUMMARY

STEM CELL NICHE

\title{
Stromal Gli2 activity coordinates a niche signaling program for mammary epithelial stem cells
}

\section{Chen Zhao, ${ }^{*}$ Shang Cai, ${ }^{*}$ Kunyoo Shin, Agnes Lim, Tomer Kalisky, Wan-Jin Lu,} Michael F. Clarke, Philip A. Beachy $\dagger$

INTRODUCTION: The stem cell niche is a complex signaling microenvironment that acts locally to sustain stem cell activity in tissue maintenance and regeneration. Although the cellular constitution and signaling activity of the stem cell niche is coming into focus in a variety of tissues, genetic regulatory factors that specify the niche are less clear. The activity of such factors is particularly intriguing in organs such as the breast, where the niche provides local signals for tissue homeostasis but also must be entrained by circulating hormones that induce the dramatic changes of puberty.

RATIONALE: The epithelial stem cells of a variety of organs respond to secreted signals generated in subjacent stromal cells, in a manner often dependent on activity of the Hedgehog (Hh) signaling pathway. Gli2, which encodes the major transcriptional effector of $\mathrm{Hh}$ signaling, is expressed in a subset of stromal cells adjacent to the ductal epithelium of the mouse mammary gland and is highly expressed at terminal end buds and end structures of the pubertal and adult mammary gland, respec- tively, which represent the sites of mammary epithelial stem cells.

RESULTS: Stromal ablation of a conditional $G l i 2^{\mathrm{fl}}$ allele with $F s p 1^{\mathrm{Cre}}$, a stromally expressed recombinase allele (producing Gli $2^{\Delta \mathrm{S}}$ mice), caused a delay in mammary ductal development, reduced the number of mammary gland stromal cells and volume of extracellular matrix, and caused abnormal mammary duct distension. Stromal Gli2 ablation did not alter development of the ovary or pituitary, nor their production of mammatrophic hormones such as estrogen or growth hormone, but did affect ductal regeneration, as indicated by a fivefold decrease in outgrowth efficiency of mammary stem cells (MaSCs) transplanted into Gli2 ${ }^{\Delta \mathrm{S}}$ mammary glands. These findings suggest that Gli2 specifies a stromal niche signaling program that critically regulates MaSC activity. FACS-isolated mammary stromal cells showed Gli2-dependent expression of factors that stimulate epithelial stem cell renewal, ductal outgrowth, and morphogenesis, including specific members of the IGF, WNT, FGF, and HGF families

of secreted peptides. Single-cell analysis showed expression of these factors in a subset of stromal cells in a manner dependent on Gli2 function. Receptors for the mammatrophic hormones

\section{ON OUR WEBSITE}

Read the full article at http://dx.doi. org/10.1126/ science.aal3485 mammary stromal niche cells is to render these cells responsive to systemic mammatrophic hormones. Supporting this conclusion, mammary gland implants of polymer fragments releasing IGF1 and WNT2 rescued Gli2 ${ }^{\Lambda \mathrm{S}}$ ductal growth phenotypes, whereas growth hormone-releasing polymer did not.

CONCLUSION: We find that the Hedgehog pathway transcriptional effector GLI2 specifies a stromal cell niche signaling program that supports mammary epithelial stem cells in pubertal and virgin adult mice. This program includes expression of factors such as IGF and WNT, and GLI2 acts in part by causing expression of receptors for hormones such as estrogen and growth hormone, thus entraining local stem cell niche activity to systemic mammatrophic hormones. Our work illustrates the central role of the stromal niche in controlling epithelial stem cell activity and suggests that niche failure may underlie pathogenesis of certain diseases, including the deficient breast development and hormonal insensitivity associated with the human disorder, combined pituitary hormone deficiency.

The list of author affiliations is available in the full article online. *These authors contributed equally to this work.

†Corresponding author. Email: pbeachy@stanford.edu Cite this article as C. Zhao et al., Science 356, eaal3485 (2017). DOI: 10.1126/science.aal3485

Stromal GLI2 coordinates mammary stem cell niche signaling program. Transcriptional regulation by Hedgehog pathway effector GLI2 in stromal cells of the mammary gland coordinates a hormone-responsive niche signaling program that directs epithelial stem cell activity during the changes of puberty (schematic, left). Gli2-deficient stromal cells in mouse mammary are unable to support normal ductal outgrowth and morphogenesis of transplanted, green fluorescent protein-labeled stem cells (right).
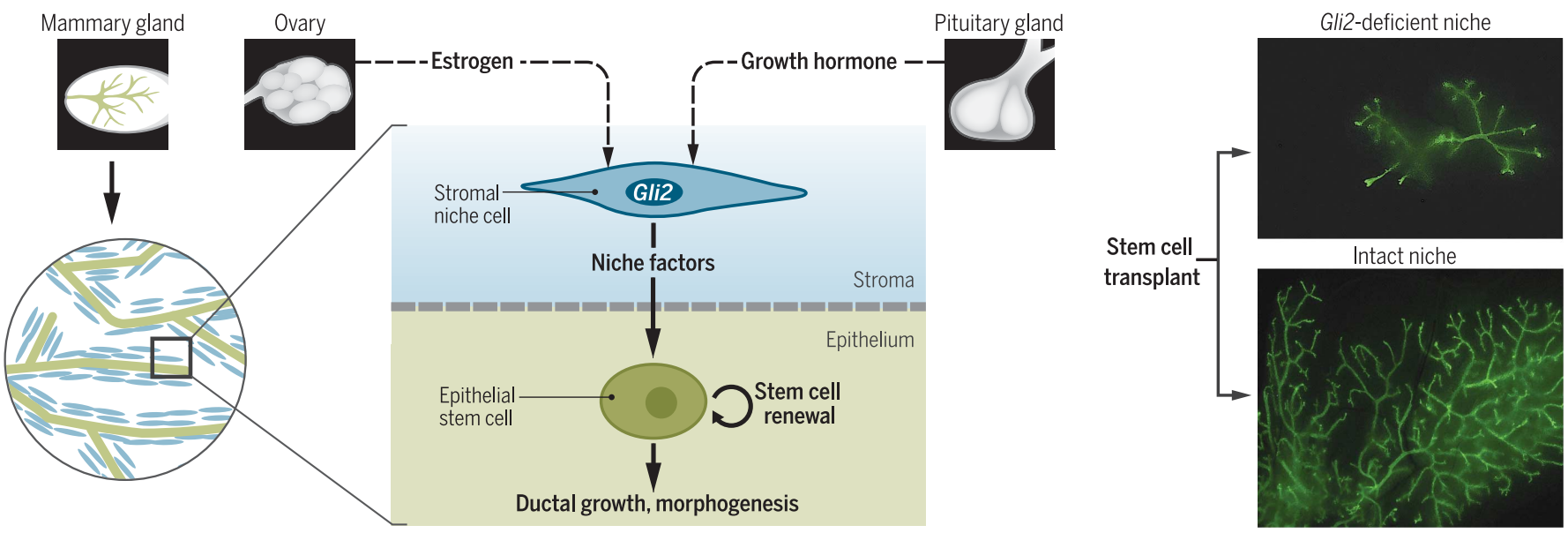
RESEARCH ARTICLE

STEM CELL NICHE

\section{Stromal Gli2 activity coordinates a niche signaling program for mammary epithelial stem cells}

\author{
Chen Zhao, ${ }^{1,2 *} \dagger$ Shang Cai, ${ }^{1 *}$ Kunyoo Shin,, ${ }^{1,2,3}$ Agnes Lim, ${ }^{1,4}$ Tomer Kalisky, ${ }^{5}$ \\ Wan-Jin Lu, ${ }^{1,2}$ Michael F. Clarke, ${ }^{1}$ Philip A. Beachy ${ }^{1,2,4,6} \neq$
}

The stem cell niche is a complex local signaling microenvironment that sustains stem cell activity during organ maintenance and regeneration. The mammary gland niche must support its associated stem cells while also responding to systemic hormonal regulation that triggers pubertal changes. We find that Gli2, the major Hedgehog pathway transcriptional effector, acts within mouse mammary stromal cells to direct a hormoneresponsive niche signaling program by activating expression of factors that regulate epithelial stem cells as well as receptors for the mammatrophic hormones estrogen and growth hormone. Whereas prior studies implicate stem cell defects in human disease, this work shows that niche dysfunction may also cause disease, with possible relevance for human disorders and in particular the breast growth pathogenesis associated with combined pituitary hormone deficiency.

\footnotetext{
I
} he Hedgehog $(\mathrm{Hh})$ signaling pathway regulates embryonic patterning and postnatal homeostasis of multiple tissues (1-3), acting via its major transcriptional effector, GLI2. A specific function for Gli2 in ductal morphogenesis of the mammary gland was suggested by the defects noted in $\mathrm{Gli}^{-/-}$mutant mouse embryonic mammary gland rudiments engrafted into adult hosts (4). In addition, breast underdevelopment at puberty is associated with the human disorder CPHD (combined pituitary hormone deficiency) (5), a substantial subset of which is caused by loss-of-function or trans-dominant mutations of the GLI2 gene (6-8). In contrast, Gli2 function appears to be dispensable for embryonic specification of mammary gland rudiments, which instead shows a requirement for expression of the GLI3 repressor of Hh pathway targets in underlying somitic mesoderm (1, 9-12). Adding further complexity to the role of Hh pathway activity, Gli2 is expressed in the epithelium of embryonic mammary gland rudiments, whereas Gli2 expres-

\footnotetext{
Institute for Stem Cell Biology and Regenerative Medicine, Stanford University School of Medicine, Stanford, CA 94305 , USA. ${ }^{2}$ Department of Biochemistry, Stanford University School of Medicine, Stanford, CA 94305, USA. ${ }^{3}$ Department of Life Sciences, Pohang University of Science and Technology, Pohang, Gyumgbuk 37673, South Korea. ${ }^{4}$ Department of Developmental Biology, Stanford University School of Medicine, Stanford, CA 94305, USA. ${ }^{5}$ Faculty of Engineering and Institute for Nanotechnology and Advanced Materials, Bar-Ilan University, Ramat Gan 52900, Israel. ${ }^{6}$ Howard Hughes Medical Institute, Stanford University School of Medicine, Stanford, CA 94305, USA.

*These authors contributed equally to this work. PPresent address: Department of Genetics and Genomic Sciences, Icahn School of Medicine at Mount Sinai, New York, NY, USA. ‡Corresponding author. Email: pbeachy@stanford.edu
}

sion in pubertal and virgin adult mice occurs exclusively in stromal cells (12).

\section{Periductal Gli2 expression in developing mammary}

To investigate the role of Gli2 in postnatal mammary gland growth, we examined Gli2 expression in the developing gland and manipulated its activity through genetic ablation or hyperactivation. Gli2 expression occurs intermittently along mamend buds of the pubertal gland (5 weeks; Fig. 1, $\mathrm{A}$ and $\mathrm{B}$ ) and at terminal structures of the adult female gland (10 weeks; Fig. 1, E and F). These regions of the pubertal and adult ducts undergo extensive proliferation and have been suggested as sites for mammary epithelial stem cells (13-18). Gli2-expressing cells in cross sections of mammary ducts appear restricted to stromal regions in both pubertal (Fig. 1, C and D) and adult mammary gland (Fig. 1, G and H), as previously reported (12), and in adult male mammary gland as well (fig. S1A). This stromal pattern of Gli2 RNA and protein expression was confirmed by quantitative polymerase chain reaction (qPCR) and Western blot assays of fluorescence-activated cell sorting (FACS)-sorted stromal versus luminal or basal epithelial cells (Fig. 1, I and J, and fig. S1B). The close proximity of Gli2 expression to mammary ducts (Fig. 1, A to $\mathrm{H}$ ) suggests the possibility of an inductive influence from epithelium in mediating stromal Gli2 expression. Such an inductive effect was confirmed by the absence of $\beta$-galactosidase ( $\beta$-Gal) expression in cleared mammary fat pads of $G l i 2^{\mathrm{nLacZ} /+} ; N S G$ mice (Fig. $1 \mathrm{~K}$, left panel) and appearance of stromal $\beta$-Gal expression upon transplantation of cleared fat pads with FACSmary ducts, and is highly enriched at terminal isolated mammary epithelial cells (Fig. 1K, right panel, blue arrowheads; see Methods). We found that transforming growth factor- $\beta 1$ (TGF $\beta 1$ ), expressed in mammary epithelial cells (19), markedly induced expression of Gli2 in FACS-isolated stromal cells in vitro in a dose-dependent manner (4.5-fold and 8-fold at 5 and $50 \mathrm{ng} / \mathrm{ml}$, respectively; Fig. 1L). The dependence of Gli2 expression on TGF 1 signaling was confirmed in vivo by a 2.2 -fold reduction of mammary gland stromal Gli2 mRNA upon treatment of mice with the TGF $\beta$ receptor (TGFBR) inhibitor, LY2109761 (Fig. 1M). Response to TGF $\beta$ does not include expression of Gli2 in the mammary epithelium; this and other differences in epithelial versus stromal responses may help account for the complexity of TGF $\beta$ effects on mammary development and in carcinogenesis (19).

\section{Stromal Gli2 in pubertal mammary development}

To genetically ablate Gli2 function in stromal cells by site-specific recombination, we examined the extent of coincident expression of $\beta$-Gal from the $G l i 2^{\text {nLacZ }}$ reporter with Cre recombinase from the $F s p I^{\mathrm{Cre}}$ allele of the fibroblast specific protein 1 gene. In mice of the genotype $F s p 1^{\mathrm{Cre}}$; Rosa $26^{\mathrm{mTmG} /+} ;$ Gli $^{\text {nLacZ }}$, Cre recombinase causes a switch of expression of the membrane-associated red fluorescent protein $\mathrm{mT}$ to expression of the membrane-associated green fluorescent protein $\mathrm{mG}$ (fig. S1C). In these mice Gli2 promoter activity, indicated by expression of $\beta$-Gal, is enriched in mG-expressing cells (fig. S1D), and a quantitative comparison revealed that most cells expressing $\beta$-Gal from the $G l i 2^{\text {nLacZ }}$ allele also expressed $\mathrm{mG}$ $\left(73 \pm 12 \%\right.$; Fig. $2, \mathrm{~A}$ and B). The $F s p 1^{\mathrm{Cre}}$ driver thus appears suitable for Cre-mediated ablation of a floxed conditional allele of Gli2 $\left(G l i 2^{\mathrm{fl}}\right)$ in stromal cells of the mammary gland, which is the exclusive site of Gli2 expression in mammary glands of pubertal and virgin adult females. $F s p I^{\text {Cre }}$ combined with $G l i 2^{\mathrm{A} / \mathrm{l}}$ or $G l i 2^{\mathrm{A} / \mathrm{nL} \text { ac }}$, hereafter referred to as Gli2 $^{\Delta \mathrm{S}}$ (genetic ablation of Gli2 is characterized in fig. S2A) produced a significant delay of mammary gland development at pubertal stages (5 weeks; fig. S2B). By adult stages, $G l i 2^{\Delta \mathrm{S}}$ mice gradually developed a hypoplastic mammary gland with greatly enlarged ducts and severely disrupted terminal end structures (6 to 10 weeks; Fig. $2 \mathrm{C}$ and fig. S3). Histological examination and FACS analysis further revealed reduced levels of type I, type II, and type IV collagen fibers and a fivefold reduction in periductal stromal cells (2.3\% versus $10.9 \%$; Fig. $2 \mathrm{E}$ and fig. S2C). The combined ductal and stromal abnormality, as measured by the ratio of ductal diameter to stromal thickness (ductal:stromal ratio or DSR), was highly significant in Gli $2^{\Delta \mathrm{S}}$ mice (Fig. 2D).

To examine the effect of increased Gli2 activity, we used $F s p 1^{\mathrm{Cre}}$ to drive stromal expression of $S m o^{\mathrm{M} 2}$, which encodes a constitutively activating form of the seven-transmembrane Smo component of the Hedgehog pathway $(20,21)$, in mice of the genotype $F_{s p} 1^{\mathrm{Cre}} ; R 26^{\mathrm{SmoM} 2}$. These mice had a maximum life span of 12 weeks (fig. $\mathrm{S} 4 \mathrm{~A}$ ) but, in sharp contrast to $G l i 2^{\Delta \mathrm{S}}$, displayed a marked expansion of the mammary gland stromal compartment, as indicated by increased collagen 


\section{Gli2 $2^{\text {Lacz/+ }}$}
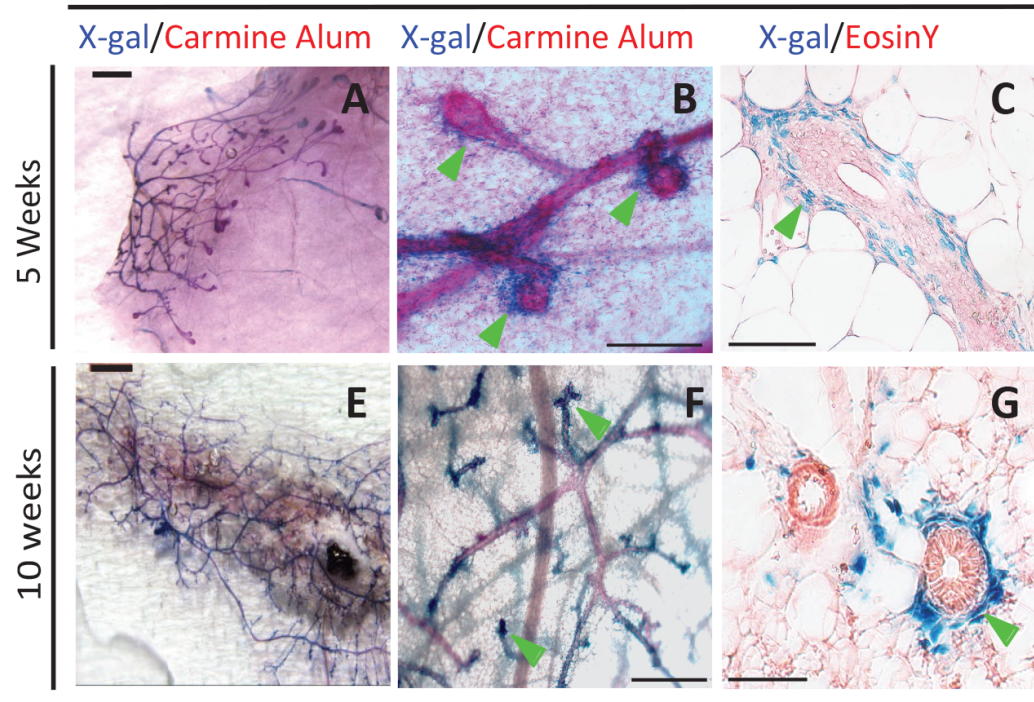

C $\beta-$ Gal CK14 DAPI

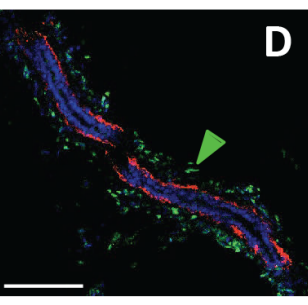

G

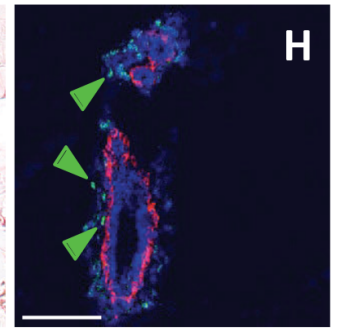

H

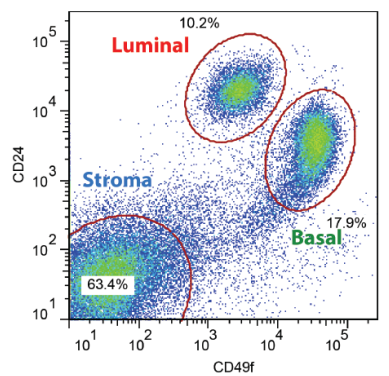

J Gli2 expression in mammary cells

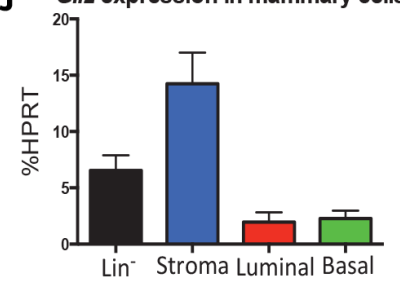

K

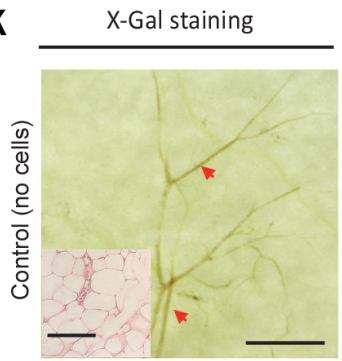

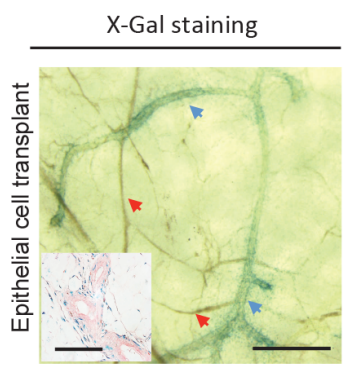

$\mathbf{L}$

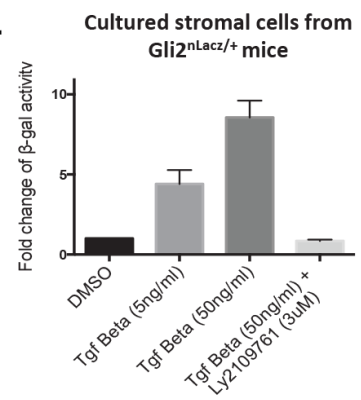

Fig. 1. Gli2 expression in mammary is restricted to stroma and induced by TGF $\boldsymbol{\beta}$. (A and $\mathbf{B}, \mathbf{E}$ and $\mathbf{F}$ ) Representative whole-mount carmine alum stains and $\beta$-Gal activity stains (X-Gal) of the fourth mammary gland of $\mathrm{Gli}^{\text {nLacZ/+ }}$ mice at 5-week-old pubertal (A and B) or 10-week-old adult ( $E$ and F) stages ( $n=6$ animals for each stage). Note heavier X-gal staining at terminal structures (arrowheads). Scale bar, $500 \mu \mathrm{m}$. (C and $\mathbf{G}$ ) X-gal/Eosin counterstain and ( $\mathbf{D}$ and $\mathbf{H}$ ) $C K 14 / \beta-G a l$ immunofluorescence stain of cross sections showing stromal expression of Gli2 (arrowheads). Scale bar, $50 \mu \mathrm{m}$. (I and $\mathbf{J}$ ) Stromal cells, epithelial basal cells, and epithelial luminal cells from 10-week-old mice $(n=5)$ were FACS-isolated and analyzed by qRT-PCR for Gli2 mRNA expression. Gli2 levels were 6.6, 14.2, 2.0, and 2.3\% for total lineage ${ }^{-}\left(\right.$Lin $\left.^{-}\right)$, stromal, luminal, and basal epithelial cells, respectively. (K) X-Gal staining showing epithelial cell-induced stromal Gli2 ${ }^{\text {nLacZ }}$ expression in mammary whole mount (scale bar, $1 \mathrm{~mm}$ ) and in EosinY counterstained mammary sections (insets; scale bar, $50 \mu \mathrm{m}$ ). Red arrows point to the vasculature, and blue arrows point to the transplanted epithelial ducts. $n=3$ mice ( 6 transplants) per condition. (L) FACS-sorted mammary stromal cells derived from Gli2 ${ }^{\text {nLacZ/+ }}$ mice were stimulated as indicated, and representative changes of $\beta$-Gal activity were measured and normalized to control samples. $n=3$ replicates per condition. (M) Gli2 qPCR analysis showing reduction of Gli2 transcripts in FACSisolated mammary stromal cells of mice treated with TGF $\beta$ inhibitor, LY2109761, for 5 days as compared with vehicle treatment ( $n=3$ mice per treatment). expression, a 20-fold increase in the percentage of stromal cells expressing the proliferative marker Ki67 (1.2 \pm 0.5 versus $23 \pm 4)$, and increased expression of Gli1 (fig. S4, B to D). Both the stromal expansion and proliferative effects of stromal $S m o^{\mathrm{M} 2}$ expression were reversed by additional ablation of Gli2, which functions downstream of $S m o$, in mice of the genotype $F s p 1^{\mathrm{Cre}} ; R 26^{\mathrm{SmoM}}$; $\mathrm{Gli}^{\mathrm{fl} / \mathrm{fl}}$. This reversal demonstrates that $S m o^{\mathrm{M} 2}$ effects are dependent on Gli2. The contrasting effects of Gli2 genetic ablation or hyperactivation indicate that the overall abundance of stromal elements within stromal cells is dictated by the presence and activity of Gli2.

\section{Stromal Gli2 supports mammary stem cell activity}

The developmental delay and terminal defects in mammary ducts of $G l i 2^{\Delta \mathrm{S}}$ mice suggested that ductal epithelial cell proliferation might be impaired. We indeed noted a qualitative decrease in epithelial staining for the Ki67 indicator of proliferative activity in adult mammary gland sections from $G_{l} 2^{2 \mathrm{~S}}$ mice (fig. S5A) and further found by quantitative FACS-based analysis a 2.6-fold reduction of epithelial cells labeled by incorporation of the nucleoside analog EdU (5-ethynyl$2^{\prime}$-deoxyuridine) in $G l i{ }^{\Lambda \mathrm{S}}$ as compared to $G l i 2^{\mathrm{WT}}$ mice $(1.3 \%$ versus $0.5 \%$; Fig. $3 \mathrm{~A})$. In contrast, markers indicative of epithelial differentiation were not significantly different in their expression in immunofluorescence staining (fig. S5A), and the relative proportions of FACS-isolated luminal versus basal populations in $G l i 2^{\Delta \mathrm{S}}$ mice were not notably different from Gli2 ${ }^{\mathrm{WT}}$ mice (lower right panels in fig. S5A). To further investigate reduced levels of proliferation, we cultured mammary epithelial cells from Gli2 ${ }^{\Delta \mathrm{S}}$ and
$G l i 2^{\mathrm{WT}}$ mice ex vivo in a Matrigel-based colonyforming assay. We found that primary epithelial cells from $\mathrm{Gli}_{2}{ }^{\mathrm{WT}}$ mice formed three times as many colonies as cells from $\mathrm{Gli}^{\Lambda \mathrm{S}}$ mice (Fig. 3B). Collectively, these data indicate that removal of Gli2 in $\mathrm{FspI}^{\mathrm{Cre} /+}$ stromal cells leads to a defect in the proliferation of the mammary epithelium.

The growth and regeneration of mammary epithelium depend on the activity of mammary epithelial stem cells (MaSCs), functionally characterized by measurement of mammary repopulating units (MRUs) upon transplantation of FACS-isolated cells into cleared mammary fat pads $(22,23)$. The activity of MaSCs depends critically upon signals provided by the mammary stroma (24). As MaSCs are enriched in myoepithelium $(22,23)$, the basal layer of the mammary epithelium that directly contacts the stromal environment, we sought to investigate how stromal 
A

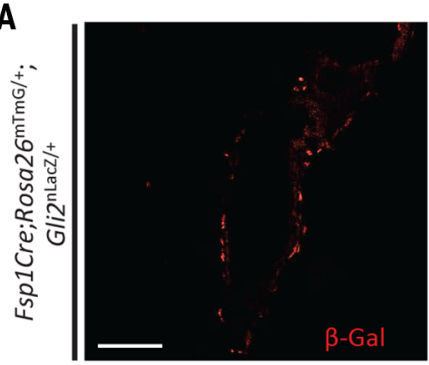

C

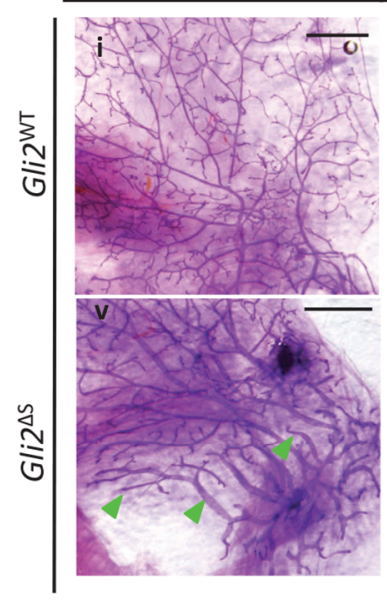

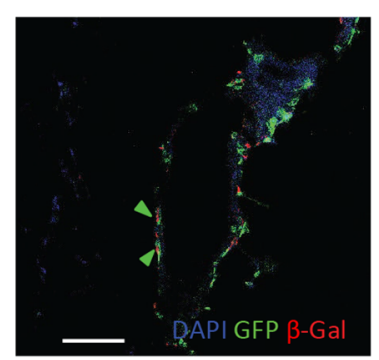

$\mathrm{ROI}$

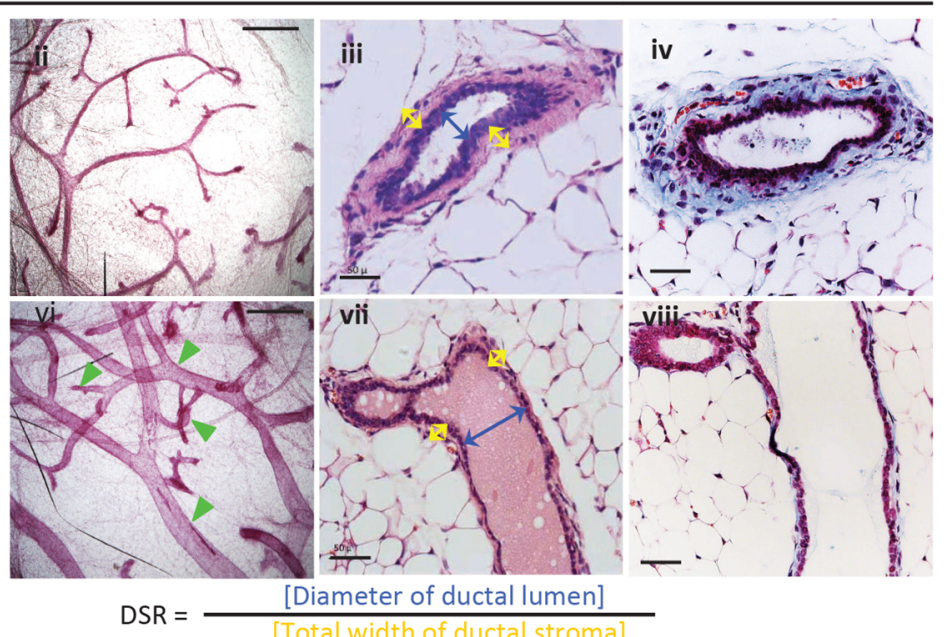

B

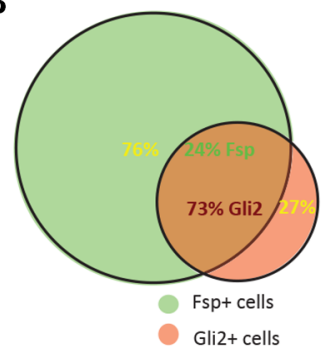

$H \& E$
D

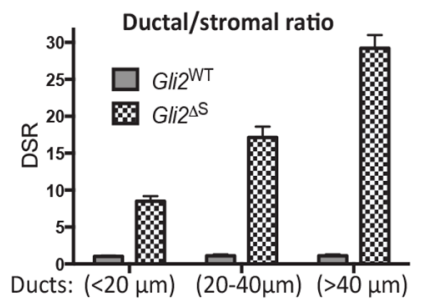

E
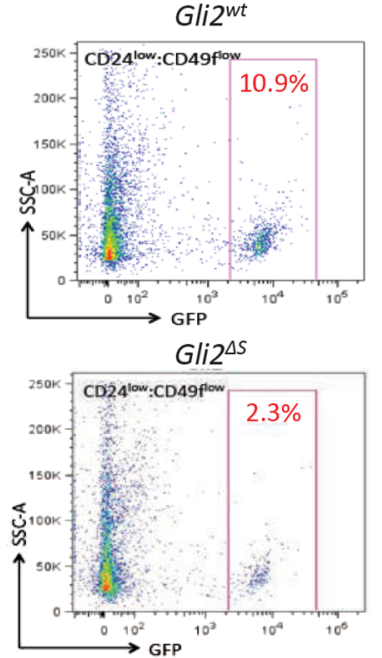

Fig. 2. Stromal Gli2 activity is essential for normal mammary development. (A) Representative immunostaining showing coincident stromal cell

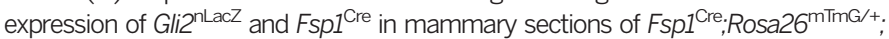
Gli2 ${ }^{\text {nLacZ/+ }}$ mice. Gli2-expressing cells were pseudocolored in red. Membranelocalized mGFP encircles nuclear-localized $\beta$-Gal. Scale bar, $50 \mu \mathrm{m}$. (B) Venn diagram showing that $F_{s p 1} 1^{\text {Cre }}$-expressing cells include the majority $(73 \pm 12 \%)$ of Gli2-expressing cells as well as other stromal cells. (C) Representative whole-mount carmine alum staining of second and third mammary glands (i, v) and selected regions of interest (ROI; ii, vi), and H\&E staining (iii, vii), and trichrome staining (iv, viii) of second and third mammary glands in 10 -week-old Gli2 ${ }^{\mathrm{WT}}$ and Gli $^{\Delta \mathrm{S}}$ littermate mice. Enlarged ducts and disrupted terminal structures in Gli2 ${ }^{\Delta S}$ are apparent (arrowheads in v, vi). The ductal-to-stromal ratio (DSR, panels iii, vii) is defined as the diameter of the ductal lumen (blue) divided by the total width of ductal stroma (yellow). Scale bars, 1 mm (i, v), $200 \mu \mathrm{m}$ (ii, vi), $50 \mu \mathrm{m}$ (iii, iv, vii, viii). (D) DSR score, as defined in (C), for ducts of the indicated width classes in Gli2 ${ }^{\mathrm{WT}}$ versus Gli2 ${ }^{\Delta \mathrm{S}}$ mice. A significantly higher DSR of ducts in various width classes is shown associated with Gli2 ${ }^{\Delta S}$ mice (10 ducts of the indicated width within each class from the second and third mammary glands of littermate mice were analyzed). (E) Representative analysis of FACS-isolated stromal cells from littermate Gli2 ${ }^{\mathrm{WT}}$ versus Gli $^{\Delta \mathrm{S}}$ mice $(n=5)$ for expression of $F_{s p 1} 1^{\text {Cre }}$-activated mGFP. A fivefold reduction of Fsp1-labeled stromal cells in the Gli $^{\Delta \mathrm{S}}$ mammary gland is shown. loss of Gli2 may affect the epithelial stem cell niche. To this end, we first compared MaSCs from $G l i 2^{\mathrm{WT}}$ or $G l i 2^{\Delta \mathrm{S}}$ mice in a competitive mammary gland repopulation assay by FACS isolation of cells from the upper portion $(\sim 50 \%)$ of the basal epithelial cell population $\left(\mathrm{Lin}^{-} \mathrm{CD} 24^{+} \mathrm{CD} 49 \mathrm{~h}^{\text {high }}\right.$; Fig. 1I) of $G l i 2^{\Delta \mathrm{S}}$ or littermate $G l i 2^{\mathrm{WT}}$ mice; these upper basal epithelial cells, enriched in MaSCs $(22,23)$, are fluorescent red, as $\mathrm{mT}$ expression is not affected by the stromal $F s p I^{\mathrm{Cre}}$ driver. These red fluorescent cells were mixed with similarly FACS-isolated green fluorescent cells [expressing enhanced GFP (EGFP)] from control mice, and the mixtures were injected into the left and right cleared fat pads, respectively, of recipient NSG animals (Fig. 3C). Within 9 weeks of transplantation, the red fluorescent cells from $\mathrm{Gli}^{\mathrm{WT}}{ }^{\mathrm{WT}}$ mice contributed to the regenerated ductal tree to the same extent as green fluorescent control cells (44\%:56\%), whereas red fluorescent cells from the Gli2 $^{\Delta \mathrm{S}}$ mice contributed minimally (7\%:93\%) (Fig. 3, C and D, and fig. S5B). Cross sections of mammary ducts from these transplanted animals showed no notable differences in periductal stromal cells and no ductal enlargement in the outgrowths derived from epithelial cells of $G l i 2^{\mathrm{WT}}$ or Gli2 ${ }^{\Delta \mathrm{S}}$ mice (Fig. 3C). Thus, MaSCs derived from the upper basal epithelial population from $\mathrm{Gli}^{\Delta \mathrm{S}}$ mice are defective in their regenerative activity, with reduced colony-forming potential in vitro (Fig. 3B) and a substantially impaired ductal outgrowth potential in vivo in competitive transplantation experiments (Fig. 3C).

To further examine the effect of stromal Gli2 function on MaSCs, we measured MRUs of FACSisolated upper basal epithelial cells from GFPexpressing mice upon transplantation into cleared mammary fat pads of $G l i 2^{\Delta \mathrm{S}}$ or $G l i 2^{\mathrm{WT}}$ littermate mice (Fig. 3E). We found that transplantation into control host animals with at least one $G l i 2^{\mathrm{WT}}$ allele in their mammary stroma generates ductal outgrowths fivefold more efficiently as compared to $G_{l i 2}{ }^{\Lambda \mathrm{S}}$ hosts (outgrowth efficiencies: 1/618 versus 1/2920; Fig. 3F). Ductal outgrowth in $G l i 2^{\Delta \mathrm{S}}$ mice was limited to a small area $\left(<20 \mathrm{~mm}^{2}\right)$, and these outgrowths were often malformed, with enlarged mammary ducts and a thin layer of stromal cells (Fig. 3E and fig. S5C) with reduced Gli2 expression (fig. S5D). Notably, the difference in MaSC functional activity measured in these transplantation assays is solely a function of the Gli2 status of the host stromal environment, as the donor cells are from mice that are wild-type except for expression of GFP. These findings thus suggest that the Gli2 activity in FSP1+ cells controls a niche-signaling program that regulates mammary stem cell activity and that this program is disrupted in $G l i 2^{\Delta \mathrm{S}}$ mice.

\section{Locally acting factors mediate stromal Gli2 activity}

In addition to input from local stromal cells, mammary morphogenesis and the MaSC pool are also regulated by other factors, including the systemic hormonal environment (25) as well as immune cell surveillance (26). We therefore investigated the possibility that Gli2 activity in other cells or 
A EDU in mammary epithelial cells

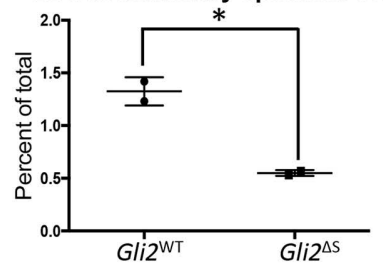

B

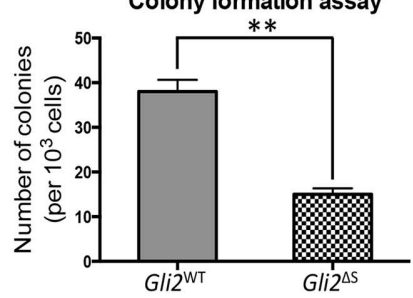

D

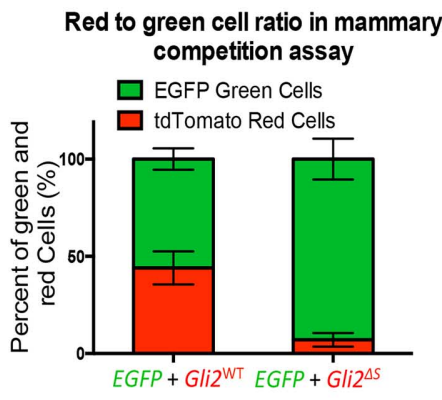

Fig. 3. Stromal Gli2 supports mammary epithelial stem cell regeneration. (A) Percentage of EDU ${ }^{+}$mammary epithelial cells as determined by FACS analysis 5 hours after EDU injection from Gli2 ${ }^{\mathrm{WT}}$ ( Gli $^{\mathrm{flox} /+}$ ) and $\mathrm{Gli}^{\mathrm{AS}}$ (Fsp1 ${ }^{\text {Cre: }}: G_{\text {li2 }}{ }^{\text {LLacZ/flox }}$ ) littermate mice ( $n=5$ per genotype). (B) Colonies formed per $10^{3}$ input epithelial cells within 10 days of culture in Matrigel were measured in triplicate from five individual Gli2 ${ }^{\mathrm{WT}}$ or Gli2 ${ }^{\Delta \mathrm{S}}$ mice. (C and D) A $\mathrm{Lin}^{-} \mathrm{CD} 24^{+} \mathrm{CD} 49 f^{\mathrm{hi}} \mathrm{GFP}^{+}$basal epithelial cell population enriched in MRU was FACS-isolated from EGFP mice and mixed with similarly isolated $\mathrm{Lin}^{-} \mathrm{CD} 24^{+} \mathrm{CD} 49 \mathrm{fh}^{\mathrm{h}}$ tdTomato ${ }^{+}$ basal epithelial cells from Gli2 ${ }^{\mathrm{WT}}$ or Gli2 $^{\Delta \mathrm{S}}$ mice for competitive repopulation assays. Cell mixtures transplanted into bilateral pairs of cleared fat pads were analyzed for outgrowth after 9 weeks. In the representative outgrowths shown, the red epithelial cells from Gli2 $^{\mathrm{WT}}$ mice generate a higher proportion of the outgrowth ( $44 \pm 8.5 \%$ ) as compared to red epithelial cells derived from Gli ${ }^{\Delta \mathrm{S}}$ mice $(7 \pm 3.5 \%)$. Scale bar, $2 \mathrm{~mm}$. No differences in stromal abundance were noted in trichrome staining of cross sections of repopulated mammary glands. Scale bar, $50 \mu \mathrm{m}$. Ten independent transplants into five NSG animals per condition were used to generate the bar graph in Fig. 2D. (E) $\mathrm{Lin}^{-} \mathrm{CD} 24^{+} \mathrm{CD} 49 \mathrm{f}^{\mathrm{hi}} \mathrm{GFP}^{+}$cells were FACS-isolated, serially diluted, and transplanted into cleared fat pads of immunocompromised (NSG) Gli2 ${ }^{\text {WT }}$ or Gli2 ${ }^{\Delta S}$ mice. Outgrowths were analyzed by whole-mount immunostaining, with representative images shown for outgrowths from transplantations of 2000 cells (E). Cross sections show no differences of CK14/CK8 expression in ducts grown in NSG;Gli2 ${ }^{W T}$ or NSG;Gli2 ${ }^{\Delta S}$ hosts, although ducts in NSG;Gli2 ${ }^{\Delta S}$ hosts were distended. Scale bars, $5 \mathrm{~mm}$ (whole mount) and $50 \mu \mathrm{m}$ (sections). (F) Results from transplantation of a range of cell numbers are shown as total outgrowths and as the proportion of these outgrowths that are greater than $20 \mathrm{~mm}^{2}$ in size. Outgrowth efficiency is calculated on the basis of total outgrowths by L-Calc ${ }^{\text {TM }}$ software of StemCell Technologies. Data are presented as mean \pm SEM, and significance was calculated by an unpaired Student's $t$ test $\left({ }^{*} P<0.05 \%\right.$, $\left.{ }^{* *} P<0.01\right)$.
C

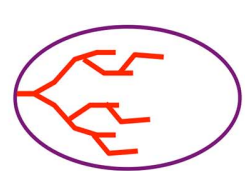

Red epithelial cells: Gli2WT

(Fsp1Cre;Rosa26 $6^{\mathrm{mTm} /+}$ )

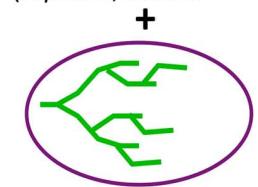

- transplant

GFP tdTomato

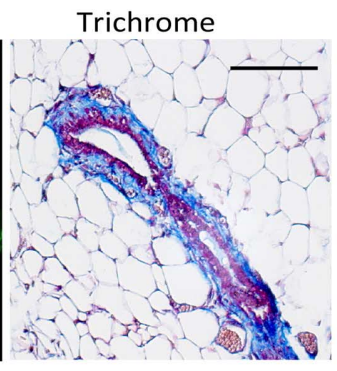

Green epithelial cells: Gli2WT
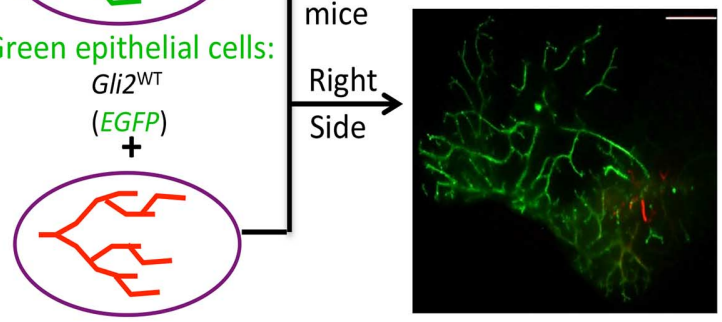

Red epithelial cells: Glizss

(Fsp1Cre;Rosa26 ${ }^{\mathrm{mTmG} /+} ;$ Gli2 $^{\mathrm{f} / \text { nlacz }}$ )
$\mathbf{E}$

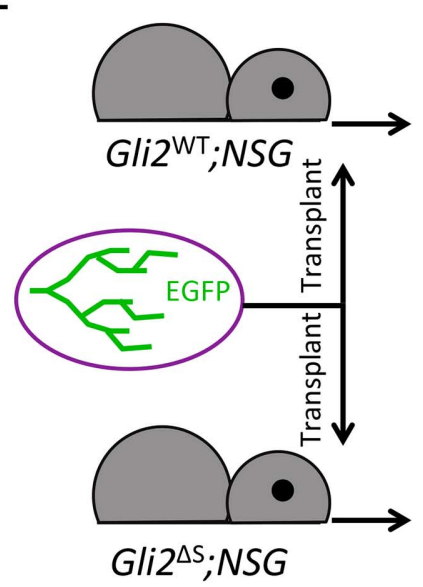

GFP

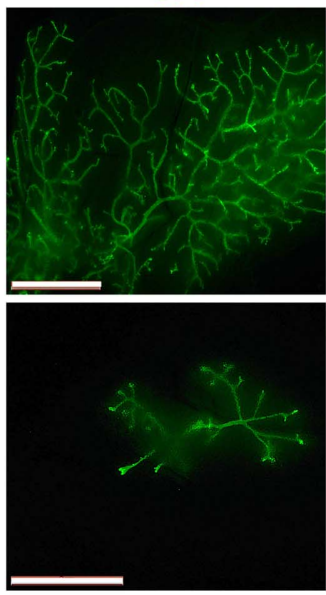

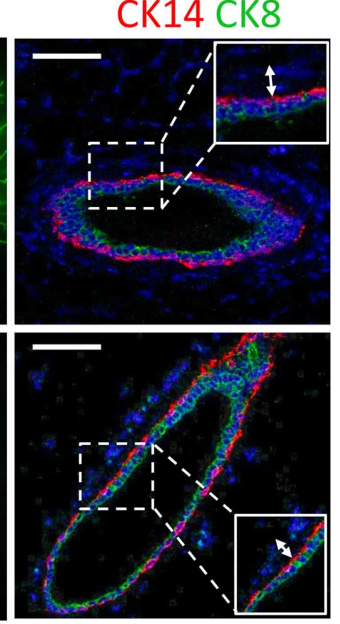

$\mathbf{F}$

\begin{tabular}{|c|c|c|c|c|}
\hline $\begin{array}{l}\text { Donor: CAG-EGFP } \\
\text { CD24 } 4^{+}{\text {CD } 49 \text { frigh: }^{+} \text {GFP }}^{+}\end{array}$ & $\begin{array}{l}\text { Cells/ } \\
\text { fat pad }\end{array}$ & Out-growths & Fat pad filled & $\begin{array}{l}\text { Outgrowth } \\
\text { efficiency } \\
(95 \% \text { Cll }\end{array}$ \\
\hline \multirow{4}{*}{ 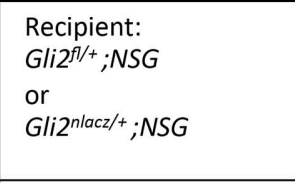 } & 50 & $3 / 8$ & $x 1 \bigcirc \times 2 \bigcirc x 5$ & \multirow{4}{*}{$\frac{1}{618(375-1017)}$} \\
\hline & 500 & $5 / 9$ & $x_{2} \times x_{3} \bigcirc x 4$ & \\
\hline & 1000 & $7 / 9$ & $\times 3$ & \\
\hline & 2000 & $9 / 10$ & Xx6 $x_{3} \bigcirc x_{1}$ & \\
\hline \multirow{4}{*}{$\begin{array}{l}\text { Recipient: } \\
\text { Fsp1cre;Gli2f//lacz;NSG } \\
\text { or } \\
\text { Fsp1cre;Gli2f/ff ;NSG }\end{array}$} & 50 & 0/6 & $x_{6}$ & \multirow{4}{*}{$\frac{1}{2920(1436-5938)}$} \\
\hline & 500 & $2 / 9$ & $x_{2} \bigcirc x 7$ & \\
\hline & 1000 & $3 / 8$ & $D \times 1 \bigcirc \times 2 \bigcirc \times 5$ & \\
\hline & 2000 & $3 / 8$ & D $x 1 \bigcirc \times 2 \bigcirc \times 5$ & \\
\hline
\end{tabular}

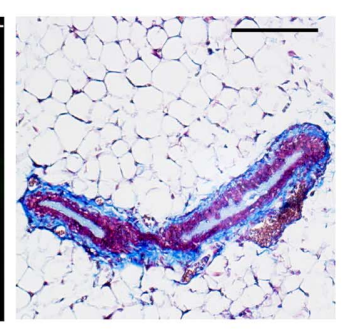


Fig. 4. Stromal Gli2 ablation does not affect mammatrophic ovarian or pituitary hormones. (A to D) Staining for $\beta$-Gal and FSP1/S100a4 was performed in a Gli2 $^{\text {LLacZ/+ }}$ mouse ovary. $\beta$-Gal (green), FSP1/S100A4 (red), and nuclei (DAPI, blue) are shown in corpus luteum ( $A$ and $B$ ) and follicle (C and D). Quantitative analysis ( $B$ and $D$ ) involved counting more than 2000 cells. Scale bar, $100 \mu \mathrm{m}$. (E) Serum from Gli2 ${ }^{\mathrm{WT}}(n=12)$ and $\mathrm{Gli}^{\Delta \mathrm{S}}(n=8)$ mice was collected and probed for estrogen level by ELISA. No significant difference was found between wt and Gli2 $^{\Delta S}$ mutant groups $(P=0.5)$. $(\mathbf{F})$ Representative H\&E (left) immunostaining (middle and right) showing that Gli2expressing cells are distinct from Fspl ${ }^{\text {Cre. }}$ labeled cells in the anterior lobe of pituitary gland in Fspl $^{\text {Cre }}$ :Rosa26 ${ }^{\mathrm{mTmG} /+}$,
A

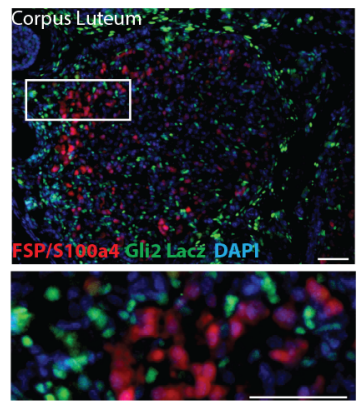

C
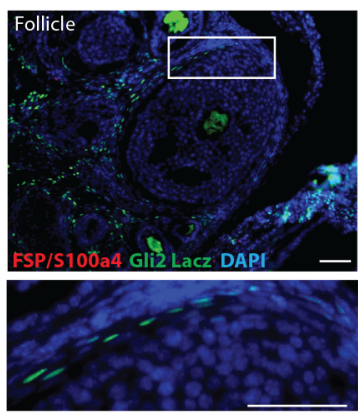

B

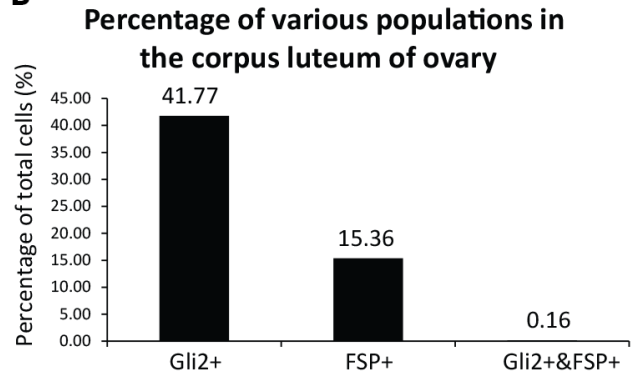

D
E

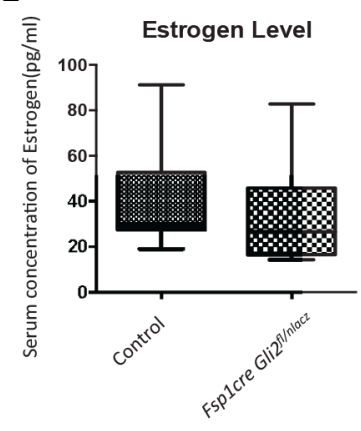

Percentage of various populations in the follicle of ovary
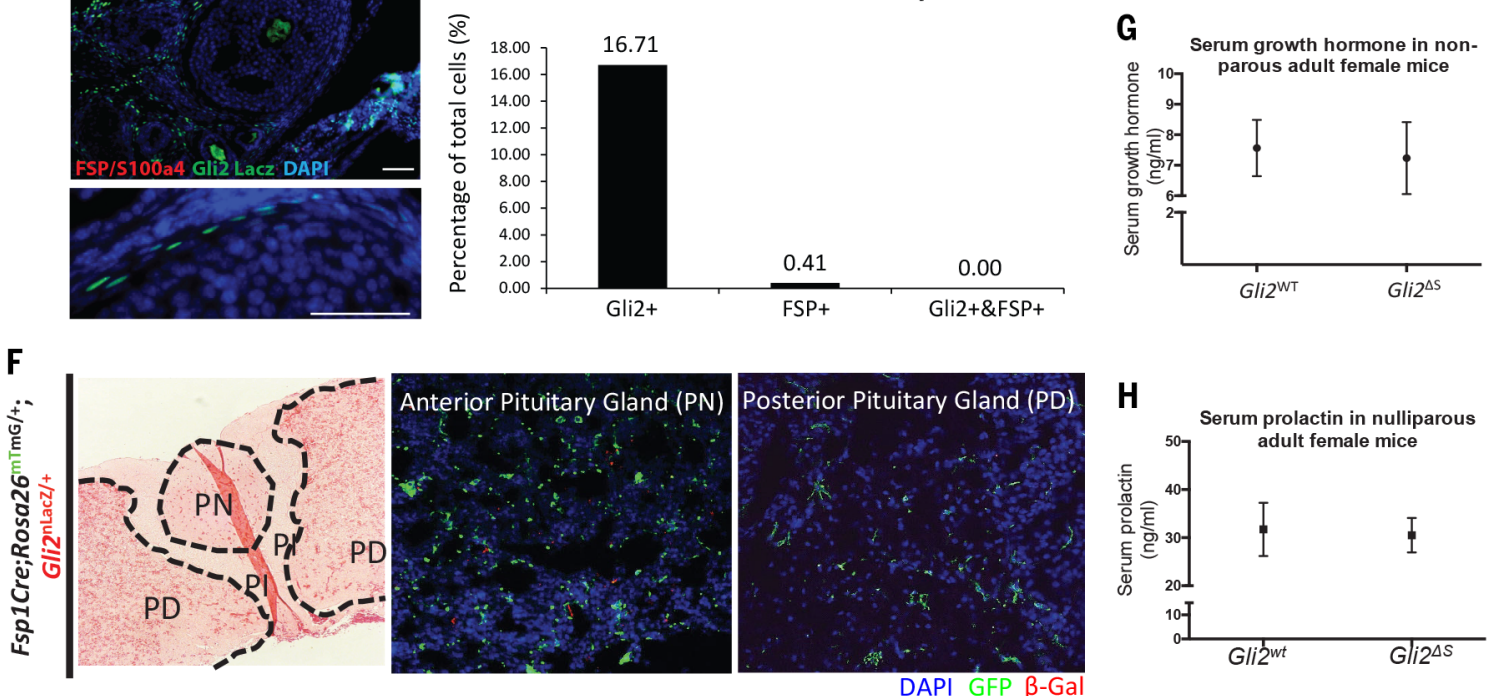

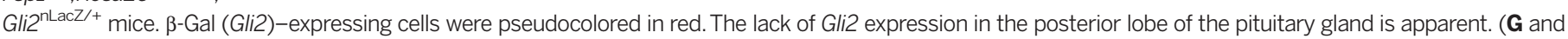
H) Quantification of growth hormone and prolactin levels in serum by ELISA in Gli2 ${ }^{W T}$ or Gli2 ${ }^{\Delta S}$ mice.

organs affects mammary development. To this end, we first analyzed coexpression of $F s p 1$ and Gli2 in ovary, the major organ for female hormone production (e.g., estrogen and progesterone). We observed few double-positive cells in corpus luteum $(0.16 \%, n=1927)$, and no coexpression in follicles $(0 \%, n=2418)$ (Fig. 4 , A to D), suggesting that Gli2 ablation is a rare event in the ovaries of our $\mathrm{Gli}^{\Delta \mathrm{S}}$ mice. In addition, and consistent with the lack of Fsp1 and Gli2 coexpression in ovary, Gli2 ${ }^{\mathrm{WT}}$ and $G l i 2^{\Delta \mathrm{S}}$ mice had statistically indistinguishable estrogen levels (Fig. 4E, $P=0.5$ ) that were comparable to those previously reported (27). We similarly noted little coexpression of FspI and Gli2 in the pituitary and no significant change in serum growth hormone (GH) or prolactin levels (Fig. 4, F to $\mathrm{H}$ ). These data collectively suggest that the $G l i 2^{\Delta \mathrm{S}}$ mice maintain a hormonal environment similar to that of $G l i 2^{\mathrm{WT}}$ littermates during development.

We next investigated potential coexpression of Fsp1 and Gli2 in mammary macrophages, which are reported to play a role in mammary development during puberty (26). Although we did observe Gli2 expression in a minuscule fraction ( $1 \%)$ of mammary cells expressing the macrophage marker F4/80 (Fig. $5 \mathrm{~A}, n=1247$ ), we detected no
Fsp1 expression in F4/80+ cells (Fig. 5B, $n=1248$ ), indicating that $F_{s p 1}{ }^{\mathrm{Cre}}$-driven ablation of Gli2 in mammary macrophages is highly unlikely. To further exclude a possible defect in mammary macrophages in the Gli2 ${ }^{\Delta \mathrm{S}}$ phenotype, we transplanted wild-type stromal cells or macrophages into the mammary fat pads of pubertal $G l i 2^{\Delta \mathrm{S}}$;NSG recipient mice (Fig. 5C). We noted that although stromal cells successfully rescued ductal enlargement with restoration of periductal collagen and extracellular matrix (Fig. $5, \mathrm{C}$ to $\mathrm{F}, n=3$ ), macrophage transplantation did not provide any rescuing activity. These results suggest that macrophages contribute little if anything to the epithelial activity lost in $G l i 2^{\Delta \mathrm{S}}$ mice. Furthermore, the sufficiency of locally implanted stromal cells to rescue the Gli2 $2^{\Delta \mathrm{S}}$ mammary phenotype excludes a role for loss of systemic factors such as pituitary or ovarian mammatropic hormones in the $\mathrm{Gli}^{{ }^{\mathrm{s \textrm {S }}}}$ mammary phenotype.

To identify stromal factors induced by Gli2 activity, we compared gene expression of FACSisolated $F s p I^{\mathrm{Cre}}$-marked stromal cells from $\mathrm{Gli}^{\Delta \mathrm{S}}$ or $G l i 2^{\mathrm{WT}}$ littermates by microarray analysis) and identified genes encoding paracrine factors such as Igf1, Wnt2, Hgf, Fgf7, and $B m p 7$; we also identified down-regulated genes encoding estrogen receptor (Esr1), growth hormone receptor (Ghr), and other genes typically expressed in stromal cells. Of particular interest among the paracrine factors, WNT signals sustain the activity of MaSCs in vivo and in ex vivo culture $(28,29)$, and functional inactivation of IgfI or its epithelially expressed receptor, Igf-Ir, leads to development of hypoplastic mammary glands with terminal end bud abnormalities $(30,31)$, similar to the defects we observe in $G l i 2^{\Delta \mathrm{S}}$ mice. The down-regulation of these genes was confirmed by qRT-PCR of bulk stromal cells from $G l i 2^{\mathrm{WT}}$ and $G l i 2^{\Delta \mathrm{S}}$ mice (Fig. 6A) and was further quantified by qRT-PCR from single cells (fig. S6; summarized in Fig. 6B). IgfI and $W n t 2$ were expressed in $7 \%$ and $9 \%$ of individual $G l i 2^{\mathrm{WT}}$ stromal cells, respectively, but in $0 \%$ of $G l i 2^{\Delta \mathrm{S}}$ stromal cells (Fig. 6B). Our single-cell analysis was validated by the expression of Gli2 in $19 \%$ of $F_{s p 1} I^{\text {Cre }}$-marked $G l i 2^{\mathrm{WT}}$ stromal cells (Fig. $6 \mathrm{~B})$, consistent with our immunofluorescence analyses (Fig. 2, A and B). The Gli2 ${ }^{\text {nLacZ }}$ reporter is expressed within the thin stromal layer that remains in $G l i 2^{\Delta \mathrm{S}}$ mice in a pattern similar to that of $G l i 2^{\text {nLacZ }}$ within control mice (Fig. $6 \mathrm{C}$ ), indicating that these cells may be correctly specified but fail to function normally, owing to loss of GLI2 protein activity. These results collectively show 
A

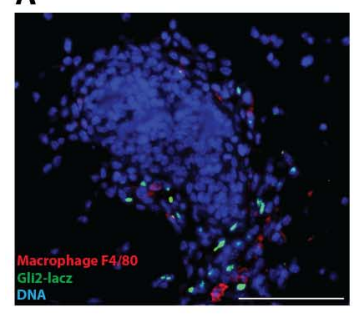

Percentage of various populations in

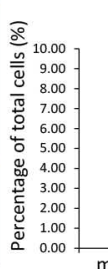
the mammary gland
C

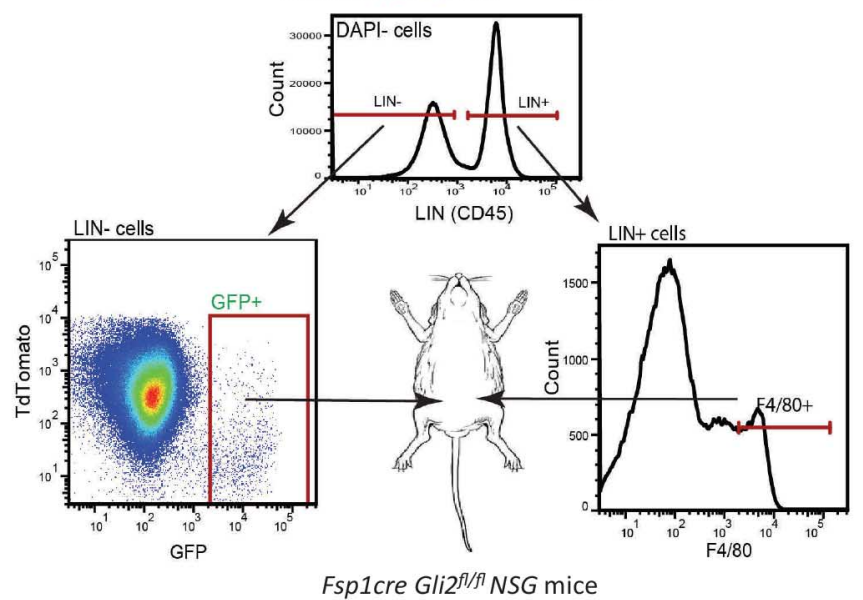

B

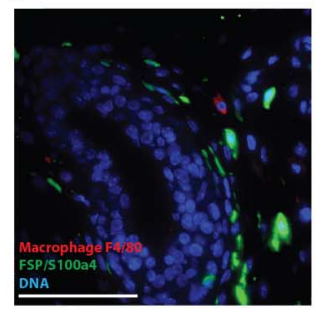

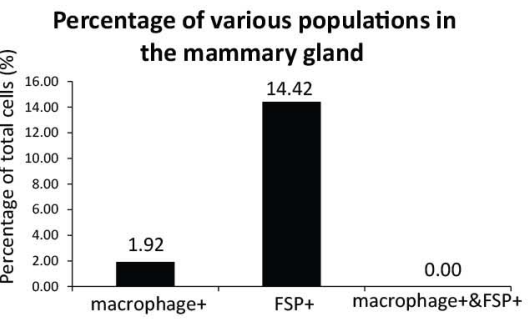

D
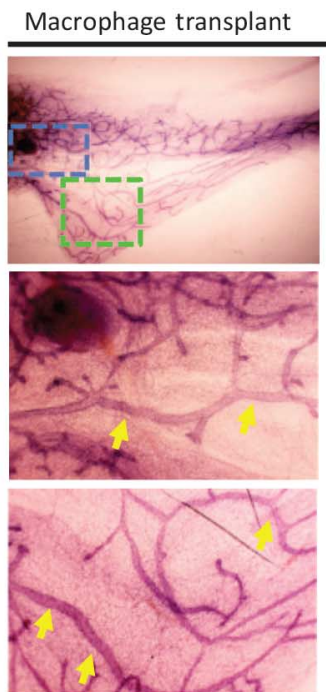

Mammary stroma transplant
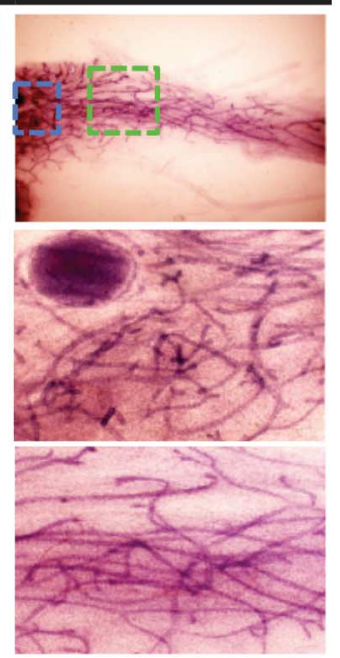

$\mathbf{F}$

Ductal/Stromal Ratio

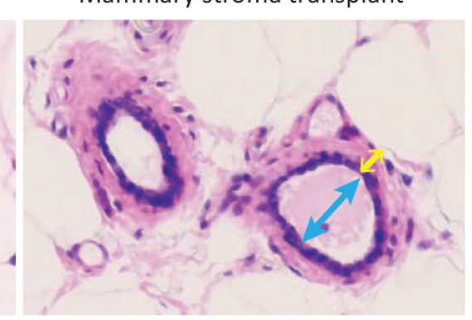

Fig. 5. Effects of Gli2 ablation in Gli2 $^{\Delta S}$ mice are mediated by mammary stromal cells. (A) Mammary gland from a 6-week-old Gli2 ${ }^{\text {nLacZ/WT }}$ mouse was paraffin sectioned and stained for $\beta$-Gal (Gli2 expression) and F4/80 (macrophage marker). Sections containing terminal end buds (TEBs) were analyzed and quantified for Gli2 (green) and macrophage (red) costaining. Scale bar, $100 \mu \mathrm{m}$. (B) Mammary gland from a 6-week-old wt mouse was paraffin sectioned and stained for FSP1/S100A4 and the macrophage marker F4/80. Sections containing TEBs were analyzed and quantified for FSP1/ S100A4 (green) and macrophage (red) costaining. Scale bar, $100 \mu \mathrm{m}$. (C)
Fsp1-expressing stromal cells and macrophages were sorted from an $\mathrm{Fspl}^{\mathrm{Cre}}$; $m T m G ; G l i 2^{\text {nLacZ/+ }}$ mouse mammary gland and injected into the fat pads of

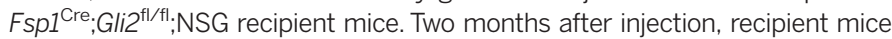
were euthanized for whole-mount analysis. (D) Fsp1-expressing stromal cells rescue mammary duct enlargement, whereas macrophages do not. $N=3$ experimental repetitions. ( $E$ and $\mathbf{F}$ ) Mammary glands from Gli $^{\Delta{ }^{\Delta S}} ;$ NSG recipients with injected donor macrophages and stroma were collected and sectioned for H\&E staining, and DSR (ratio of ductal diameter, blue arrow, to total stromal width, yellow arrow) was determined as in Fig. 2. $P<0.01$. Error bars indicate SD. that the Gli2 transcription factor is critical for expression of mammary stem cell niche signals.

\section{Mammatrophic hormone response requires stromal Gli2}

Previous studies have shown that MaSCs respond to the mammatrophic hormones estrogen and GH $(32,33)$. MaSCs do not, however, express the receptors for these hormones (34), indicating that the mammatrophic hormone effect is indirect. Mammary stroma is an important mediator of hormone effects on MaSC activity (24), and we find that expression of estrogen receptor and GH receptor is markedly reduced, from 7 and $14 \%$, respectively, to $2 \%$ of individual stromal cells in $G l i 2^{\Delta \mathrm{S}}$ mice (Fig. 6B). We therefore examined the Gli2 dependence of hormone response in FACSisolated $F s p I^{\mathrm{Cre}}$-marked mammary stromal cells and indeed found that stimulation with GH or with estrogen revealed significantly impaired induction of their target genes Igfl or $H g f$, respectively, in cells from Gli2 $2^{\Delta \mathrm{S}}$ as compared to Gli2 ${ }^{\mathrm{WT}}$ mice (2.88-fold reduction for IgfI and 3.16-fold reduction for $H g f$; Fig. 6, D and E), reflecting the significant reduction in expression of receptors for these hormones (fig. S7).

These defects in hormonal response of mammary stroma are reminiscent of the incomplete response of patients suffering from the disorder CPHD to hormonal supplementation. This supplementation is provided because multiple peptidic pituitary hormones and steroidal hormones induced by pituitary hormones are deficient as a result of the congenital hypopituitarism associated with CPHD. Supplementation with GH rescues height defects in these patients $(35,36)$, but abnormal breast development often is not improved, even with estrogen supplementation (5). Gli2 ${ }^{\Delta \mathrm{S}}$ mice produce normal levels of pituitary hormones such as GH and prolactin (Fig. 4, G and H), as Gli2 expression in the pituitary is not affected ( $F s p I^{\text {Cre }}$ and $G l i 2^{\text {nLacZ }}$ expression in the pituitary do not 
A

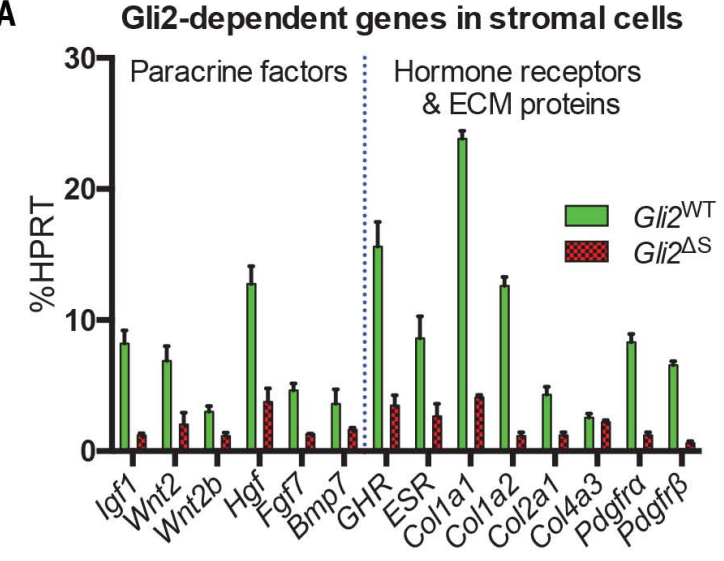

B

Stromal gene expression at single cell resolution

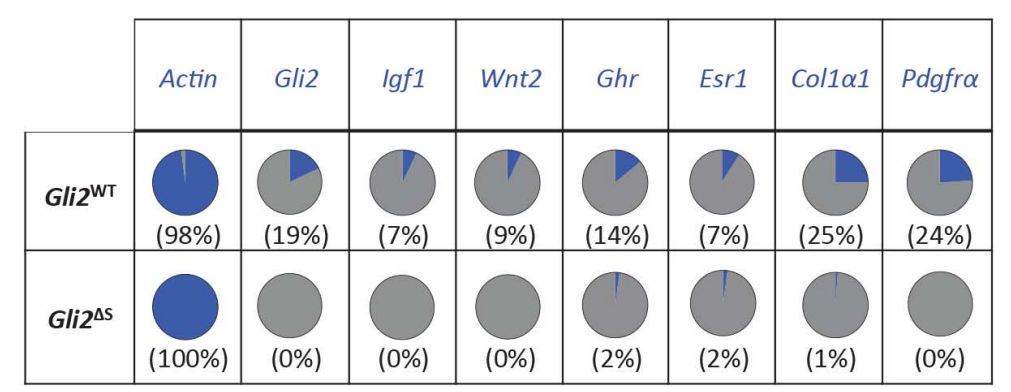

C

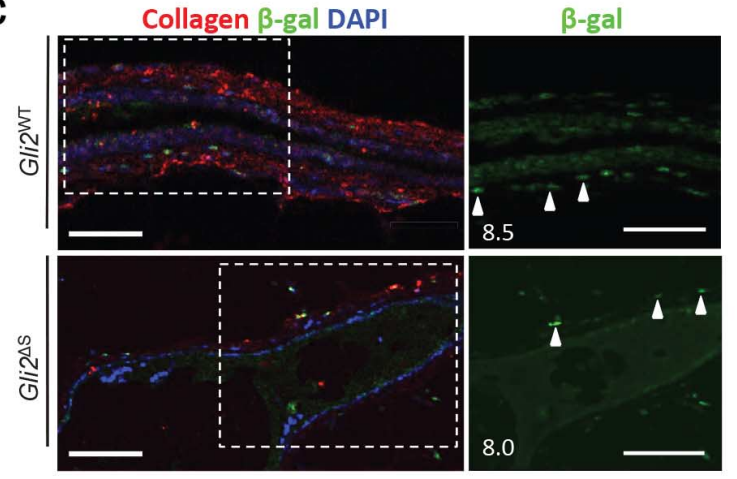

D

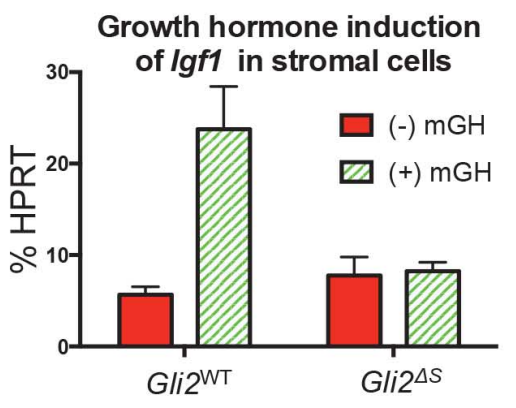

$\mathbf{E}$

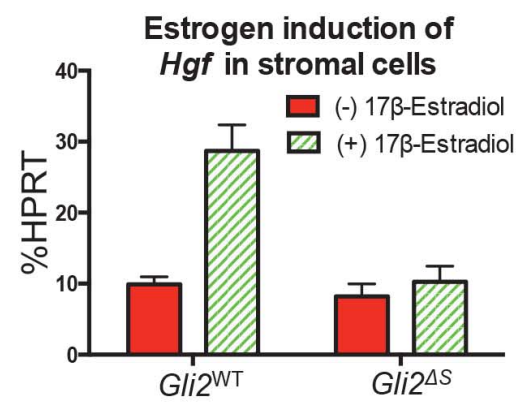

Fig. 6. Stromal Gli2 regulates a niche signaling program for mammary stem cell activity. (A) Fsp1 ${ }^{\text {Cre }}$-labeled mammary stromal cells FACS-isolated

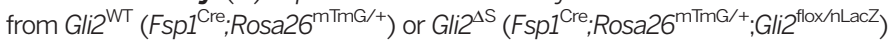
littermate mice were analyzed by qRT-PCR for expression of selected genes, shown as a percentage of HPRT expression, and measured in triplicate from each of three individual Gli2 ${ }^{\mathrm{WT}}$ or Gli2 ${ }^{\Delta \mathrm{S}}$ mice. Three major classes of stromally expressed genes are down-regulated in stromal cells of Gli2 ${ }^{\Delta \mathrm{S}}$ mice (see text).

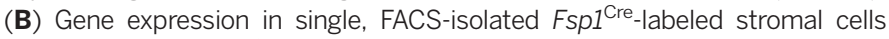
from Gli2 ${ }^{\mathrm{WT}}$ and $\mathrm{Gli}^{\Delta \mathrm{S}}$ mice was analyzed by qRT-PCR. The results (fig. S4) are summarized here as the percentage of single cells analyzed that express the indicated genes. (C) Sections of Gli2 ${ }^{\mathrm{WT}}$ ( $\mathrm{Fspl}^{\mathrm{Cre}}{ }^{\text {;Rosa26 }}{ }^{\mathrm{mTmG} /{ }^{+}} ; \mathrm{Gli}^{\mathrm{nLacZ} /+}$ ) and $\mathrm{Gli}^{\Delta \mathrm{S}}$ ( $\mathrm{Fspl}^{\mathrm{Cre}}$, Rosa22 $^{\mathrm{mTmG} /+} ;$ Gli2 $^{\text {nLacZ/flox }}$ ) mammary glands immunostained for collagen and $\beta$-Gal. Selected areas (dotted lines) are shown at higher magnification in the green channel only ( $\beta$-Gal-expressing cells) in the right panels. The frequency of $\beta$-Gal-labeled cells per $100-\mu \mathrm{m}$ length of ductal epithelium is shown in the lower left of the right panels. Scale bar, $50 \mu \mathrm{m}$. (D and E) Fsp1 ${ }^{\text {Cre }}$-labeled mammary stromal cells FACS-isolated and cultured from Gli2 ${ }^{\mathrm{WT}}$ or $\mathrm{Gli}^{\Delta \mathrm{S}}$ mice were stimulated with murine growth hormone $(\mathrm{mGH})$ (D) or 17ß-estradiol (E) for 24 hours and assayed for expression of lgf1 or Hgf, respectively. Expression of lgf1 and $\mathrm{Hgf}$ in $\mathrm{Gli}^{\Delta \mathrm{S}}$ is reduced as compared to Gli2 ${ }^{\mathrm{WT}}$. Measurements in panels (D) and (E) were made in triplicate from each of three individual Gli2 ${ }^{\mathrm{WT}}$ or Gli2 ${ }^{\Delta \mathrm{S}}$ mice. Error bars indicate SEM. overlap; Fig. 4F). Despite intact pituitary hormone production, however, Gli2 ${ }^{\Delta \mathrm{S}}$ mice nevertheless show abnormal mammary gland development, as described above. $G l i 2^{\Delta \mathrm{S}}$ mice thus do not share the pituitary hormonal deficiencies of CPHD patients but do share the resistance to hormone treatments, which likely contributes to the pathogenesis of mammary abnormalities in CPHD patients. Consistent with this interpretation, we find that $h G L I 2$, like $m G l i 2$, is expressed predominantly in stromal breast cells (fig. S8).

If, as our findings suggest, stromal Gli2 mediates hormonal response and the expression of niche signals that support epithelial stem cell activity, it should be possible to rescue mammary defects seen in $G l i 2^{\Delta \mathrm{S}}$ mice by providing missing niche signals from an exogenous source. We therefore tested the effect of slow-release polymer implants containing secreted protein signals in the intact mammary of Gli2 ${ }^{\Delta \mathrm{S}}$ mice, focusing in particular on insulin-like growth factor 1 (IGF1) and a canonical WNT family protein because of the well-established roles of these signals in mammary development (28-31), and using GH as a control. Ex vivo assays showed that GH, IGF1, and WNT2b proteins embedded in the slow-release polymer, poly(ethylene-co-vinyl acetate) (Elvax40), were gradually released over 2 to 8 days and were able to stimulate pathway-specific target genes (fig. S9, A to G). For in vivo experiments, the effects of control or factor-containing polymer implants surgically placed in the mammary glands of $G l i 2^{\Delta \mathrm{S}}$ mice were assessed after 7 days by wholemount analysis and qPCR (Fig. 7A).

We indeed confirmed, that, although GHcontaining Elvax40 implants increased the number of terminal structures fivefold in $\mathrm{Gli2}^{\mathrm{WT}}$; $\mathrm{NSG}$ host mice (5.625 \pm 1.21 ; fig. S10, B and C), in $G l i 2^{\Delta \mathrm{S}}$; NSG mice these implants failed to stimulate IgfI expression and did not change terminal structure growth at the implantation site (Fig. 7, B to D). In contrast to GH, IGF1-containing implants increased terminal structure formation in the vicinity of the implants sevenfold in pubertal (psd40) and fivefold in adult (psd70) Gli2 ${ }^{\Delta \mathrm{S}}$ mice (Fig. 7, E and
F, and fig. S10A). IGF1 target genes Egr1 and M-Csf also were reliably induced near the site of the implants (Fig. 7G), confirming the efficacy of IGF1 delivery. As compared to IGF1 alone, implants containing both IGF1 and WNT2b showed an even greater effect in inducing a 13-fold increase in terminal structure growth at the adult stage (Fig. $7, \mathrm{H}$ and I) in Gli2 ${ }^{\Delta \mathrm{S}}$ mice and consistently induced the expression of $M$-Csf and Axin2 (Fig. 7J); Axin2 expression indicates Wnt response, which promotes the survival and self-renewal ability of mammary epithelia (29). Together these results suggest that, although the mammary abnormalities in $G l i 2^{\Delta \mathrm{S}}$ mice fail to respond to GH stimulation, the terminal growth defects of the mammary ductal tree can be rescued in part by local supplementation with the GLI2-dependent paracrine factors IGF1 and WNT2b.

\section{Conclusions}

Although the cellular constitution and signaling activity of the stem cell niche is coming into focus in a variety of tissues, the genetic regulatory 
A

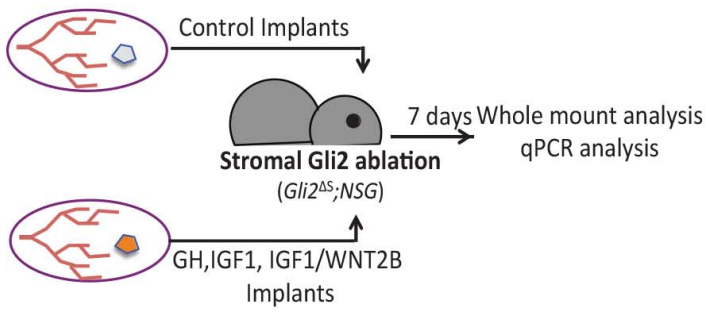

E

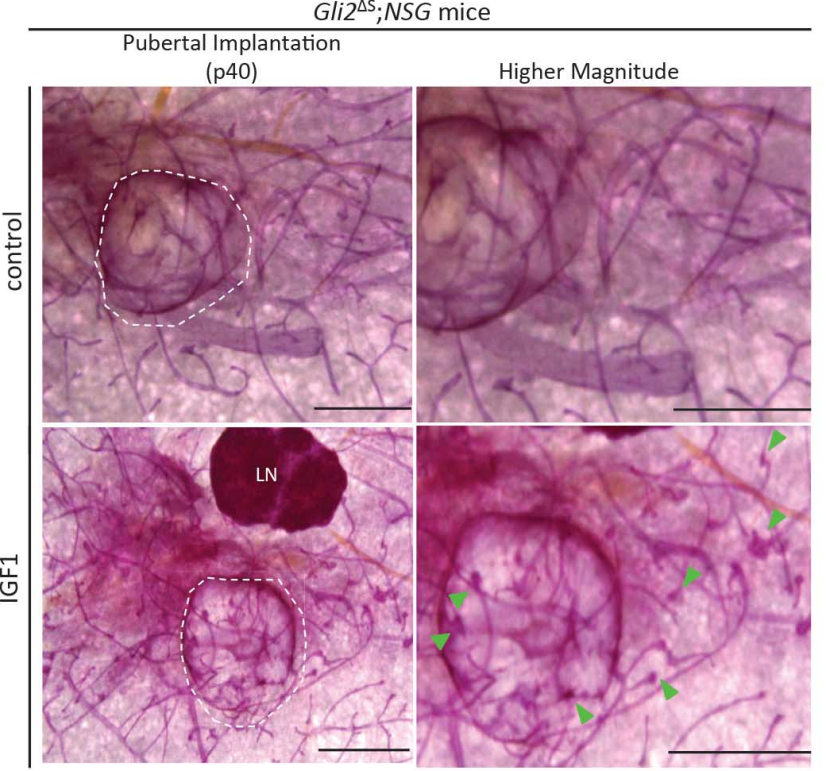

$\mathbf{F}$

\section{Induction of terminal structures}

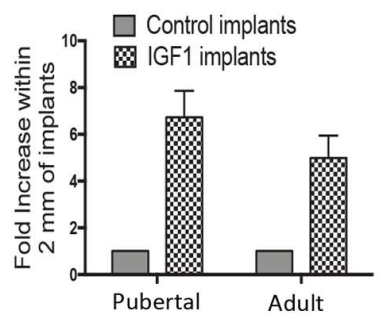

G

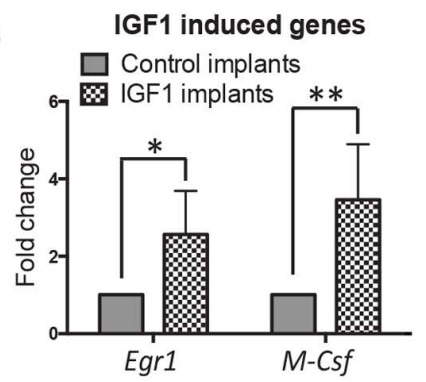

Fig. 7. Slow-release IGF1, WNT2B polymer implants rescue epithelial growth defects in Gli2 $^{\Delta \mathbf{S}}$ mice. (A) Schematic of slow-release polymerbased implantation experiments to test activity of GH, IGF1, and combined IGF1/WNT2B. (B) Control and GH-containing polymers (dashed lines) were implanted bilaterally into immunodeficient Gli2 $^{\Delta S}$ (NSG: Gli2 ${ }^{\Delta S}$ ) mice, and ductal morphology was examined 7 days after implantation $(n=3$ implantations; one representative image of three is shown). Scale bar, $1 \mathrm{~mm}$. (C) Numbers of terminal structures within $2 \mathrm{~mm}$ of the implantation site are shown as fold increase relative to control implants. (D) Induction of lgf1 induction in control and GH-containing implants. GH failed to induce terminal growth or lgf1 expression in NSG;Gli2 ${ }^{\Delta S}$ mice. (E) Control and IGF1-containing polymers (dashed lines) were implanted bilaterally into NSG;Gli2 ${ }^{\Delta S}$ mice at pubertal $(p 40)$ or adult ( $p 70)$ stages. Ductal morphology was examined after

B

Control and GH implants in Gli2 $^{\Delta S} ; N S G$ mice
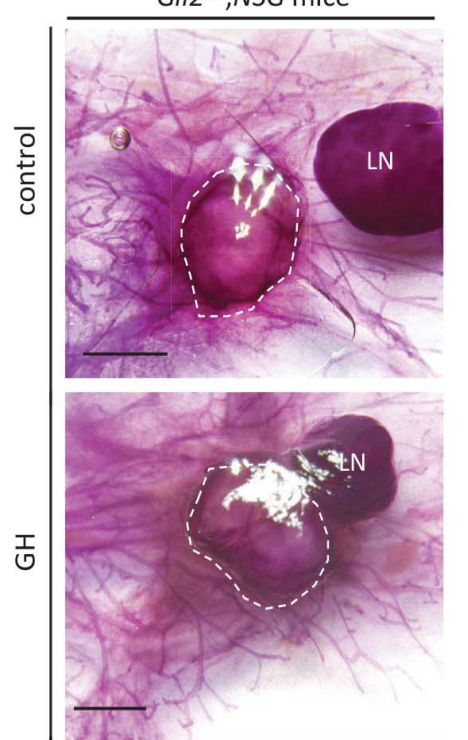

Control and IGF1/WNT2B implants

H

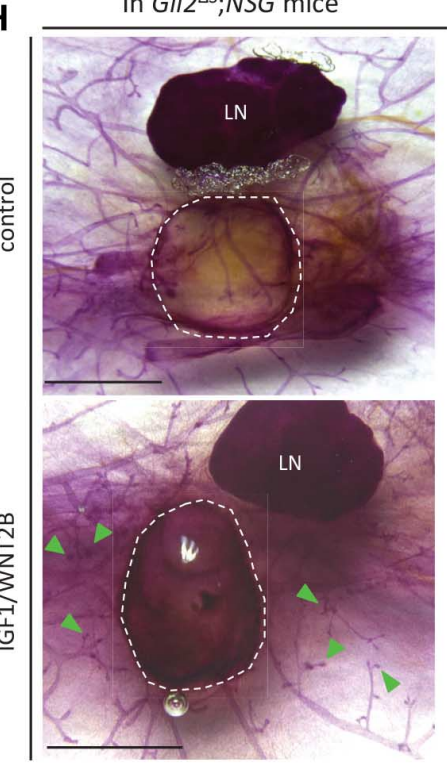

C

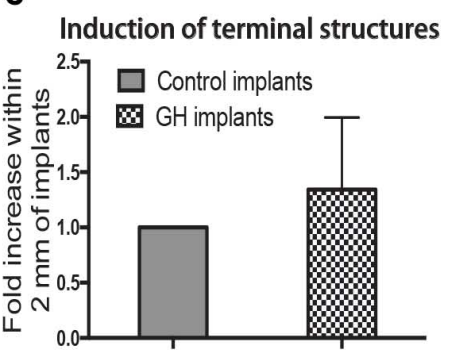

D

GH induced lgf1 expression

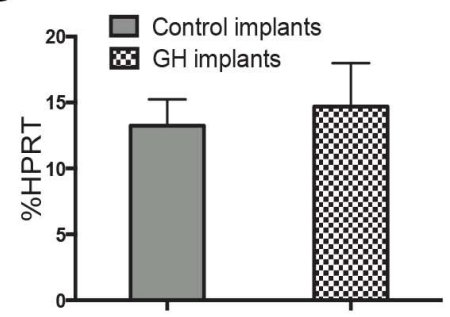

I Induction of terminal structures

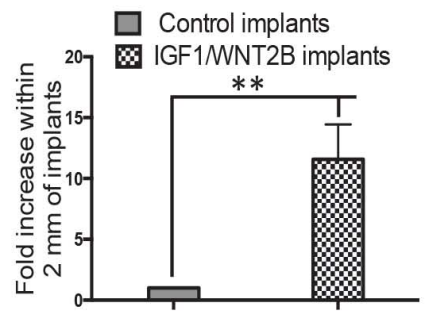

J

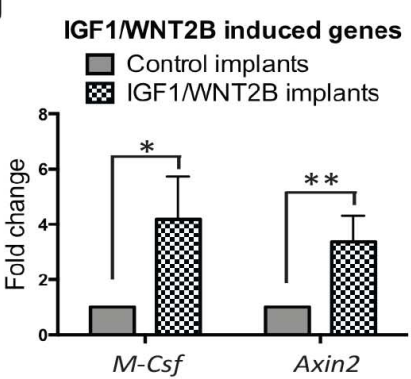

7 days ( $n=3$ implantations; one representative image of three is shown). Scale bar, $1 \mathrm{~mm}$. (F and $\mathbf{G}$ ) Numbers of terminal structures ( $F$ ) within $2 \mathrm{~mm}$ of implants and IGF1-induced expression of Egrl and M-Csf (G) were calculated and normalized to control implants. (H) Control and IGF1/WNT2b-containing polymers (dashed lines) were implanted bilaterally into NSG;Gli2 ${ }^{\Delta S}$ mice, followed by morphological analyses after 7 days ( $n=3$ implantations; one representative image of three is shown). Scale bar, $1 \mathrm{~mm}$. (I and $\mathbf{J}$ ) Numbers of terminal (I) structures and induction of IGF1 or WNT2b target genes (J) were quantified as fold increase relative to control implants. IGF1/WNT2b implants induce more terminal end growth as compared to IGF1 alone. Data are normalized to the mean values in the control and are presented as mean \pm SEM; statistical significance was calculated by an unpaired Student's $t$ test ( $P<0.05 \%$, **P $<0.01)$.

factors that specify the niche and thus create a favorable environment for stem cell function have not been identified. The activity of such factors is particularly intriguing in organs such as the breast, where the niche provides local signals for tissue homeostasis but also must be entrained by circulating hormones that induce the dramatic changes of puberty. Using a Gli2 $2^{\mathrm{nLacZ}}$ reporter and a stromal-specific Cre driver, we find that Gli2 is predominantly expressed in periductal stroma of the mammary gland of pubertal and virgin adult mice and encodes a functionally critical 


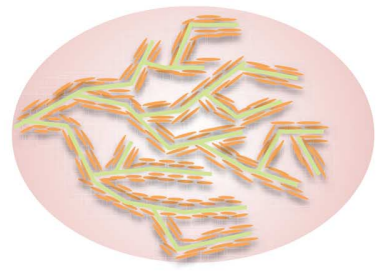

$$
\begin{gathered}
\begin{array}{c}
\text { Loss of Gli2 in } \\
\text { mammary stroma }
\end{array} \\
\hline \text { (Gli2 }{ }^{\triangle S} \text { or CPHD) }
\end{gathered}
$$
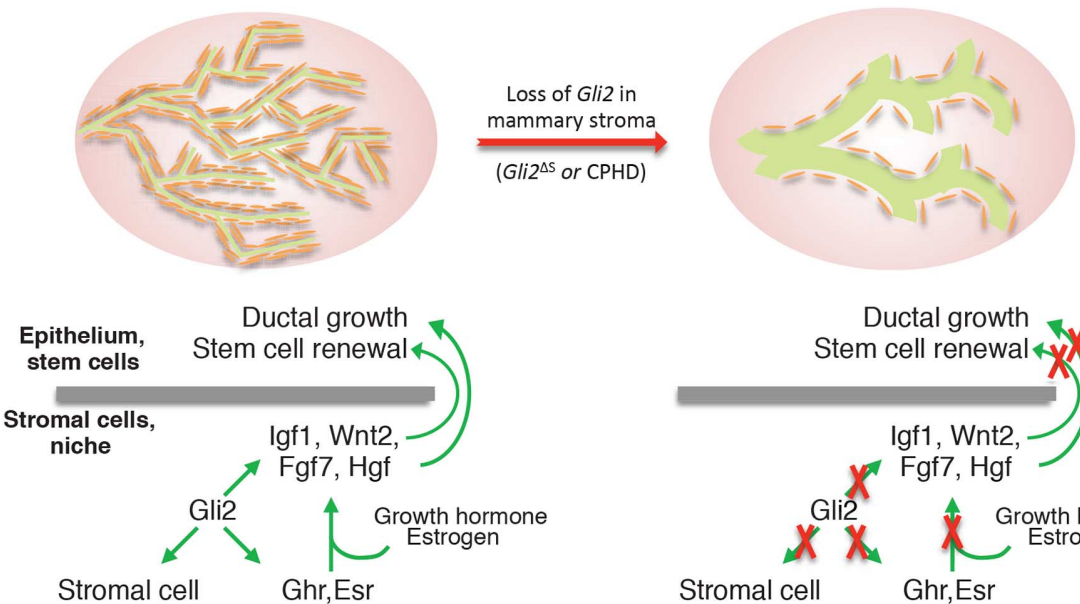

proliferation, ECM

Ghr,Esr

Fig. 8. Mammary stem cell niche dysfunction in Gli2 $^{\Delta \mathrm{S}}$ mice and CPHD patients results from stromal loss of Gli2. Normal Gli2 function in mammary stroma (left) coordinates mammary stem cell niche signaling, response to estrogen and growth hormone, and stromal expansion, leading to normal mammary stem cell maintenance and hormone-induced growth and morphogenesis at puberty. Stromal loss of Gli2 function in Gli2 ${ }^{\Delta S}$ mice or CPHD (right) leads to disruption of the niche signaling program and loss of mammatrophic hormone response at puberty.

regulator that specifies niche activity in support of mammary epithelial stem cells (Fig. 8). One aspect of this regulatory activity is the induction, direct or indirect, of stem cell support factors, including IGF and WNT signaling proteins. The GLI2 transcription factor thus appears to control the niche signaling program for MaSCs. Gli2 ${ }^{\Delta \mathrm{S}}$ mice lacking stromal Gli2 function consequently suffer from a severe defect in regenerative activity of epithelial stem cells. A second aspect of Gli2 activity is the induction of receptors for mammatrophic hormones such as growth hormone and estrogen in stromal cells such that they become competent to respond to circulating hormones, thereby placing niche signaling activity under hormonal control. This hormonal response is also lost in Gli2 ${ }^{\Delta \mathrm{S}}$ mice (Fig. 8). Thus, our analysis provides insight into the mechanism that coordinates systemic mammatrophic hormone action and activity of the local epithelial stem cell niche, namely, that a single transcription factor, GLI2, controls both the expression of hormone receptors and the stromal niche signaling program.

Our findings in $G l i 2^{\Delta \mathrm{S}}$ mice imply that a defective stem cell niche environment may underlie the pathogenesis of breast defects seen in the human disorder CPHD. Although several degenerative and aging-related diseases have been tentatively ascribed to defects in stem cells themselves, dysfunction of a supporting niche has not previously been linked to human disease (37). By indicating that niche failure can cause disease, our study asserts the central role of the niche in controlling stem cell activity and raises the possibility of niche dysfunction in other human diseases. Furthermore, by showing that Gli2dependent mammary niche signaling factors can rescue aspects of the Gli $2^{\Delta \mathrm{S}}$ mammary in mice, our work suggests a potential therapeutic inter- vention for patients with hormone-refractory CPHD.

\section{Methods \\ Mice}

Female mice at pubertal (5 weeks) or adult (10 weeks) stages were used for all experiments. $G l i 2^{\text {nLacZ }}$ mice (38) were first bred with $G l i 2^{\text {flox }}$ mice (39), then with Rosa $26^{\mathrm{mTmG} /+}$ mice (40), to generate $G l i 2^{\text {flox } / \mathrm{nLacZ}}$ or $G l i 2^{\mathrm{nLacZ} /+} ;$ Rosa $26^{\mathrm{mTmG} /+}$ mice. Fsp $I^{\text {Cre }}$ mice (4I) were crossed to $G l i 2^{\text {flox/flox }}$ to

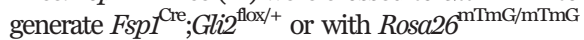
mice to generate Fsp1Cre;Rosa $26^{\mathrm{mTm} /++}$ strain. Fsp1Cre;Gli2 ${ }^{\text {flox/+ }}$ mice were then crossed with $G l i 2^{\text {flox } / \mathrm{nLacZ}}$ mice to obtain littermate $G l i 2^{\text {flox/+ }}$ and $F s p 1^{\mathrm{Cre}} ; G l i 2^{\text {flox/nLacZ }}$ mice. The $F s p 1^{\mathrm{Cre}}$; Rosa $26^{\mathrm{mTmG} /+}$ strain was crossed to $\mathrm{Gli} 2^{\text {flox/flox }}$ strain to generate Fsp1Cre;Rosa $26^{\text {mTmG//+}} ;$ Gli $^{\text {flox/+ }}$ mice which were subsequently bred to $G l i 2^{\mathrm{nLacZ} /+}$; Rosa $26^{\mathrm{mTmG} /+}$ to obtain littermate $F s p 1^{\mathrm{Cre}}$; Rosa $26^{\text {mTmG/+ }}$, Fsp ${ }^{\text {Cre }}$;Rosa $26^{\text {mTmG/+ }} ;$ Gli2 ${ }^{\mathrm{nLacZ} /+}$ and FsplCre;Rosa $26^{\mathrm{mTmG} /} ; G l i 2^{\mathrm{nLac} / / \mathrm{llox}}$ mice. NSG mice were extensively bred and back-crossed with Fsp1 ${ }^{\mathrm{Cre}} ;$ Gli $^{\text {nLacZ/flox }}$ through six generations to obtain ${ }^{\text {Gli }} 2^{\text {flox/++}} ; N S G, G l i 2^{\text {nLacZ/+ }} ; N S G, F s p 1^{\text {Cre }}$; $G l i 2^{\text {flox/flox }} ; \mathrm{NSG}$, and $\mathrm{FspI}^{\mathrm{Cre}} ; \mathrm{Gli}^{\text {nLacZ/flox }} ; \mathrm{NSG}$ mice. All mouse strains were obtained from Jackson Laboratories, except as otherwise indicated. For each experiment, mice of the same genotypes were randomly selected for experiments and investigators were blinded for outcome assessment. All procedures were performed under an assigned protocol (14586) approved by the Administrative Panel on Laboratory Animal Care (APLAC) at Stanford University.

\section{Antibodies and reagents}

The following antibodies were purchased: chicken polyclonal anti- $\beta$-Gal antibody (Abcam, CAT:ab9361), rabbit polyclonal anti-CK14 antibody (Covance,
CAT:PRB-155P), rabbit polyclonal anti-Ki67 antibody (Abcam, CAT: ab15580), Cy3-conjugated mouse monoclonal anti-smooth muscle actin antibody (Sigma, CAT: C6198), rat anti-CK8 antibody (DSHB, TROMA-I), rabbit polyclonal anticollagen I antibody (Abcam, CAT: ab21286), goat polyclonal anti-NKCC1 antibody (Santa Cruz, CAT:sc-21545), guinea pig anti-Gli2 antibody was obtained from Dr. Eggenschwiler at University of Georgia, APC (allophycocyanin)-conjugated rat anti-mouse F4/80 (Biolegend), rabbit polyclonal anti-S100a4 (Biolegend). Dylight 488-labeled goat anti-chicken IgY, Alexa 488-labeled donkey anti-rabbit immunoglobulin G (IgG) and Alexa 647labeled donkey anti-goat IgG were purchased from Jackson ImmunoResearch. Alexa 488-labeled goat anti-rabbit IgG, Alexa 594-labeled goat antirabbit IgG, and Alexa 647-labeled goat anti-rat IgG were purchased from Invitrogen. Trichrome straining kit (25088-100) was purchased from Polysciences Inc. Rat/mouse growth hormone enzyme-linked immunosorbent assay (ELISA) kit was purchased from Millipore (EZRMGH-45K). Mouse prolactin ELISA kit was purchased from Abcam (ab100736). Mouse Igf1 ELISA kit was purchased from Raybiotech (ELM-IGF1). Mouse Wnt2B ELISA kit was purchased from MYBioSource (MBS946031). Click-IT ${ }^{\circledR}$ Plus EdU Alexa Fluor ${ }^{\circledR} 647$ flow cytometry assay kit (C10634) was purchased from Invitrogen. Poly(ethylene-co-vinyl acetate) (Elvax40) beads (340502) were purchased from Sigma. Recombinant mouse Igf1 (791-MG-050) and recombinant mouse Wnt2b (customized quantity) were purchased from R\&D Systems. Mouse growth hormone (CYT-540) was purchased from Prospecbio. 48.48 Dynamic Array Chips (BMK-M.48.48) for single-cell analysis were purchased from Fluidigm. Ortho-nitrophenyl- $\beta$-galactoside (ONPG) was purchased from Thermo-Scientific (catalog no. 34055). TGFßRI/II inhibitor, LY2109761, was purchased from XCESSBIO in a customized quantity.

\section{Mammary cell preparation and flow cytometry}

Mammary glands from adult mice (10-week-old) were dissected and minced. Single-cell suspensions were made by digestion of minced tissue with culture medium [Dulbecco's modified Eagle's medium (DMEM)/F12, 5\% fetal bovine serum, $1 \%$ penicillin-stretomycin-glutamine] containing collagenase/hyaluronidase cocktail solution (StemCell Technolgies, 07912) for 3 hours at $37^{\circ} \mathrm{C}$, followed by sequential- $5 \mathrm{~min}$ treatments with red blood cell lysing buffer (Sigma, R7767), 0.25\% trypsin-EDTA, and deoxyribonuclease $(0.1 \mathrm{mg} / \mathrm{ml})$ in dispase $(0.1 \mathrm{U} / \mathrm{ml})$ with gentle pipetting. Cell suspension was then filtered through $40-\mu \mathrm{m}$ cell strainers and applied to subsequent FACS isolation. Phycoerythrin (PE)/Cy7-conjugated anti-mouse CD24 (rat, clone M1/69), APC-conjugated anti-mouse CD49f (Rat, clone GoH3), PerCP/Cy5.5 conjugated anti-mouse CD31 (rat, clone 390), PerCP/Cy5.5 conjugated anti-mouse CD45 (rat, clone 30-F11), and PerCP/Cys5.5 conjugated anti-mouseTer119 (rat, TER-119) were purchased from BioLegend. Antibodies were then incubated with strainer-filtered mammary cells in Hanks' balanced salt solution 
(HBSS) with $2 \%$ fetal bovine solution for $20 \mathrm{~min}$ on ice. All FACS analysis and cell sortings were performed using FACS aria II (Becton Dickinson).

\section{EdU flow cytometry}

In vivo EdU labeling was accomplished by intraperitoneal injection of EdU (150 $\mu \mathrm{g}$ per $10 \mathrm{~g}$ of body weight). Mammary glands were collected after 3 hours and prepared as single-cell suspensions, followed by click-it chemistry for EdU staining and surface markers-based staining (CD24-PE/Cy7, CD49f-APC, CD31-PerCP/Cy5.5, CD45-PerCP/Cy5.5, Ter119-PerCP/Cy5.5) to separate stromal, luminal, and basal populations. EdUstained cells in the stromal-negative population were then presented as a percentage of parental cells.

\section{Liquid $\beta$-Gal assay}

FACS-isolated mammary stromal cells were cultured ex vivo and treated with the indicated concentrations of TGF $\beta$ with or without TGF $\beta R / / I I$ inhibitor, LY2109761. Cells were lysed and incubated with colorimetric $\beta$-Gal substrate, orthonitrophenyl- $\beta$-galactoside (ONPG). $\beta$-Gal activity as indicated by $\mathrm{OD}_{420}$ was measured at the indicated conditions.

\section{In vitro colony-formation assay}

To compare ex vivo colony-forming activity of mammary epithelial cells derived from different backgrounds, we adopted an established 3D OnTop assay (42). Briefly, Matrigel (BD Bioscience) was thawed and applied to the bottom of 24-well plate at a volume of $120 \mu \mathrm{l}$ per well, followed by polymerization at $37^{\circ} \mathrm{C}$ for $15 \mathrm{~min}$. FACS-isolated mammary epithelial cells were resuspended in stock buffer (DMEM/F12, 10\% FBS) at a density of $2 \times 10^{5}$ cells per ml, serial diluted in Matrigel containing buffer (DMEM/F12, 10\% FBS, 50\% Matrigel), and plated on top of the polymerized Matrigel. Culture medium was changed every 48 hours. Primary colony numbers were scored after 14 days in culture, followed by sequential phosphate-buffered saline(PBS)-EDTA treatment and extraction of 3D-cultured mammary colonies into single-cell suspensions.

\section{Histology analysis}

$G l i 2^{\mathrm{WT}}$ and $G l i 2^{\Delta \mathrm{S}}$ mice were euthanized at the indicated ages. The 2nd/3rd and/or the 4th mammary glands were dissected. For whole-mount carmine alum analysis, mammary glands were fixed in Carnoy's fixative for 3 hours, followed by serial rehydration, carmine alum staining, and serial dehydration. Mammary glands were then cleared with xylenes and mounted with permount. For whole-mount X-Gal analysis, mammary glands were fixed in X-Gal fixative ( $2 \%$ paraformaldehyde, $0.2 \%$ glutaraldehyde) for $30 \mathrm{~min}$ at ambient temperature, followed by serial rehydration, overnight carmine alum staining, dehydration, and clearance with xylenes. For X-Gal staining, hematoxylin and eosin (H\&E) staining, and trichrome staining, mammary glands were fixed and cut as paraffin sections for H\&E or trichrome staining or as cryosections for $\mathrm{X}$-Gal staining. X-Gal,
H\&E, and trichrome staining on mammary sections was performed as described previously (43).

\section{Immunofluorescence and confocal microscopy}

Dissected mammary glands were fixed in $4 \%$ paraformaldehyde, serially dehydrated, and processed as 4- $\mu \mathrm{m}$ paraffin sections. Paraffin sections were cleared with xylenes, rehydrated, and subjected to antigen-retrieval in citric acid-based buffer by the pressure cooker method (44). For immunostaining, tissue sections were rinsed in PBS, then blocked in blocking solution containing $3 \%$ bovine serum albumin (BSA), $0.25 \%$ Triton X-100, and serum of the host species used to generate the secondary antibody (10\% goat serum or $10 \%$ donkey serum). An hour after blocking, diluted primary antibodies in blocking buffer were incubated with sections overnight at $4^{\circ}$ $\mathrm{C}$ in a humidified chamber. Sections were then washed three times with PBS containing 0.25\% Triton X-100 and incubated with appropriate secondary antibodies diluted 1:1000 in blocking solution for 1 hour at ambient temperature, followed by three washes and mounting with Prolong Gold mounting reagent with 4',6-diamidino-2-phenylindole (DAPI) (Invitrogen). Immunofluorescence images were obtained using a Zeiss LSM 510 inverted confocal microscope, processed for publication with Zeiss LSM5 Image Browser software, and are representative images from one of three experiments.

\section{Mammary fat pad transplantation}

FACS-isolated cells were resuspended in a cocktail buffer with 50\% DMEM/F12 (20\%FBS), 50\% Matrigel, and $0.04 \%$ Trypan Blue (Sigma). Cells were injected into cleared mammary gland fat pads of 3-week-old female mice. Repopulated mammary glands were harvested 9 weeks after transplantation. Outgrowths of repopulated mammary ductal structures were imaged under a fluorescence dissection microscope (Leica). For macrophage and stromal cell rescue assay, macrophages (identified by F4/80) and Fsp1+ stromal cells (identified by GFP) from the mammary glands of Fsp-cre Gli $2^{\text {nLacZ/wt }}$ mTmG mice were injected into the inguinal fat pads of 3-week-old $G l i 2^{\Delta \mathrm{S}}$ NSG recipient mice at 10,000 cells per gland with 50\% Matrigel + DMEM F12 medium. Two months after the injection, mammary glands were dissected and analyzed by whole-mount and immunohistochemistry (IHC).

\section{Mammary in vivo competitive repopulation assay}

Green color-labeled Lin $^{-} \mathrm{CD} 24^{+} \mathrm{CD} 49 \mathrm{f}^{\text {high }} \mathrm{GFP}^{+}$ basal cells isolated from $\mathrm{Gli}^{\mathrm{WT}}$ mice were mixed in equal number with red color-labeled $\mathrm{Lin}^{-} \mathrm{CD} 24^{+} \mathrm{CD} 49 \mathrm{f}^{\mathrm{hi}} \mathrm{GFP}^{+}$basal cells isolated from $G l i 2^{\mathrm{WT}}$ mice (green $G l i 2^{\mathrm{WT}}$ : red $G l 2^{\mathrm{WT}}$ ) or from $G l i 2^{\Delta \mathrm{S}}$ (green $G l i 2^{\mathrm{WT}}$ : red $G l i 2^{\Delta \mathrm{S}}$ ) mice. These mixtures were transplanted bilaterally into cleared mammary gland fat pads of immune-deficient NSG mice (non-obese diabetic, severe combined immunodeficiency, IL-2 gamma chain-deficient). Outgrowths in this competitive mammary repopulation assay were examined 9 weeks after transplantation.

\section{Mammary regeneration assay}

$\mathrm{Lin}^{-} \mathrm{CD} 24^{+} \mathrm{CD} 49 \mathrm{f}^{\text {hi }} \mathrm{GFP}^{+}$basal cells derived from $\mathrm{EGFP}^{+}$mice were serially diluted as indicated and transplanted into cleared mammary gland fat pads of $G l i 2^{\mathrm{WT}}$;NSG mice with at least one functional allele of $G l i 2\left(G_{l i} 2^{\text {flox/+ }} ; \mathrm{NSG}\right.$ or $G l i 2^{\text {nLacZ/+ }}$; NSG) or into Gli2 ${ }^{\Delta \mathrm{S}}$;NSG littermates $\left(\mathrm{Fspl}^{\mathrm{Cre}}{ }^{\mathrm{C}}\right.$; $G l i 2^{\text {flox/nLacZ }} ; N S G$ or $\left.F s p 1^{\text {Cre }} ; G l i 2^{\text {flox/flox }} ; N S G\right)$. Mammary outgrowth frequency and size of outgrowths were measured. Outgrowth frequency (repopulation frequency) was calculated by L-Calc software of StemCell Technologies. Owing to limited numbers of matching $G l i 2^{\mathrm{WT}} ; N S G$ and $G l i 2^{\Delta \mathrm{S}}$;NSG within a single litter, data presented in the table summarize transplantation results in mice from several different litters.

\section{RNA extraction and microarray analysis}

Total RNAs of FACS-isolated stromal population from $G l i 2^{\mathrm{WT}}$ and $G l i 2^{\Delta \mathrm{S}}$ mice were extracted by Trizol and RNeasy Plus min kit (Qiagen). Concentration and quality of extracted RNAs were determined by Agilent 2100 Bioanalyzer (Agilent Technologies). RNA samples were hybridized to the Mouse Gene 2.0 ST microarray chips and scanned in accordance with the manufacturer's protocol (data available at www.ncbi.nlm.nih. gov/geo/query/acc.cgi?acc=GSE66820). Expression values normalized and differentially expressed genes were identified by Transcriptome Analysis Console (TAC). Genes showing a fold change of $1.5\left(\log _{2}\right)$ were highlighted in functional annotation analyses. Expression changes of genes of interests by microarray analysis were validated via quantitative reverse transcription-polymerase chain reaction (RT-PCR) analysis.

\section{Single-cell FACS isolation and data analysis}

GFP-labeled mammary stromal cells of Gli2 ${ }^{\mathrm{WT}}$ and $G l i 2^{\Delta \mathrm{S}}$ mice were FACS-isolated (5000 cells per genotype), followed by single-cell FACS isolation into 96-well plates. Sorted single cells on a 96-plate format were lysed by hypotonic pressure, and mRNA expression levels (Ct, threshold cycle) of 48 genes in 48 cells were measured by microfluidic single-cell RT-qPCR reaction in two 48 by 48 format Fluidigm chips $(45,46)$ (Fluidigm, CA). Data analysis was performed with Matlab (Mathworks, MA).

\section{Slow-release polymer implantation assay}

GH, IGF1, and IGF1/WNT2B were prepared as slow-release proteins in Elvax40-based polymers (47-49). Briefly, lyophilized BSA (20 mg) alone or in a mixture with the indicated amount of $\mathrm{GH}$, IGF1, or IGF1/WNT2B were dispersed in $0.125 \mathrm{ml}$ of Elvax40 that had been dissolved in dichloromethane $(20 \% \mathrm{wt} / \mathrm{vol})$. The mixture was quickfrozen and dried in a rotary evaporator, then the polymer matrix with entrapped proteins was cut to size $(0.5$ to $1 \mathrm{mg})$ and surgically implanted. Kinetics and activities of released proteins were validated in ELISA analyses and in qPCR analyses of their target gene expression, respectively. Control Elvax40 polymer or Elvax40 polymers containing the above-mentioned proteins were 
implanted bilaterally into pubertal or adult $G l i 2^{\Delta \mathrm{S}}$ mice. Mammary ductal morphology was examined 7 days after surgery. In parallel experiments, mammary ducts in the vicinity ( 1 to $2 \mathrm{~mm}$ ) of implants were dissected and prepared as single-cell suspensions. Cells derived from various implants were plated in a 24-well Petri dish for 2 hours to deplete fibroblasts, followed by collection of supernatant enriched in epithelial cells. Total RNAs were extracted from epithelial cells and converted to cDNAs, which were then applied to genespecific (Bio-Rad) preamplification and subsequent qPCR analyses.

\section{GH, estrogen, and prolactin ELISA analyses in serum}

Peripheral blood was drawn by retro-orbital bleeding in the amount of $200 \mu \mathrm{l}$ from $G l i 2^{\mathrm{WT}}$ and $G l i 2^{\Delta \mathrm{S}}$ mice. Mice were allowed to recover for 5 days until the next collection. Blood samples were kept at ambient temperature for $30 \mathrm{~min}$, followed by centrifugation at $3000 \mathrm{rpm}$ for $10 \mathrm{~min}$. Serum in the supernatant was either used immediately for ELISA analyses or aliquoted and stored at $-80^{\circ} \mathrm{C}$ until next use. Serum samples were diluted and subjected to standard ELISA assays to determine GH or prolactin levels in accordance with the manufacturer's protocol. Differences between genotypes are considered significant if $P<0.05$. Estrogen levels of $G l i 2^{\mathrm{WT}}$ and $G l i 2^{\Delta \mathrm{S}}$ mice were determined by $17 \beta$-Estradiol ELISA kit (from Enzolifesciences) according to the manufacturer's instructions.

\section{Statistical analysis}

Statistic analysis was performed with GraphPad Prism v5. Data are presented as mean \pm SEM, and group differences were examined with a two-tailed Student's $t$ test. $P$ values were calculated on the basis of three independent experiments unless otherwise specified. A value of $P<$ 0.05 is considered statistically significant.

\section{Primers used in real-time $R T-P C R$ analysis}

Primers used for preamplification of Igfl, EgrI, $m C s f$, and Axin2 in cDNAs of dissected implants were purchased from Bio-Rad. Primers used for qPCR analyses of Col1a1, Col1a2, Col2a1, Pdgfro, $P d g f \beta$, and Esr1 were previously reported (50-52). Others were purchased as QuantiTect Primer Assays from Qiagen. QuantiTect primer assays used for real-time RT-PCR include mGli2 (QT00291711), Ghr (QT00109900), mBmp7 (QT00096026), mIgfI (QT00154469), mWnt2 (QT00118503), $m W n t 2 b$ (QT00115451), mFgf7 (QT00172004), $m H g f$ (QT00158046), mEgr1 (QT00265846), mCsf1 (QT01164324), mIl-3R $\alpha$ (QT00251293), mAxin2 (QT00126539), and mLefI (QT00148834).

\section{REFERENCES AND NOTES}

1. J. Briscoe, P. P. Thérond, The mechanisms of Hedgehog signalling and its roles in development and disease. Nat. Rev. Mol. Cell Biol. 14, 416-429 (2013). doi: 10.1038/nrm3598; pmid: 23719536

2. K. Shin et al., Hedgehog/Wnt feedback supports regenerative proliferation of epithelial stem cells in bladder. Nature $\mathbf{4 7 2}$ 110-114 (2011). doi: 10.1038/nature09851; pmid: 21389986

3. A. Lim, K. Shin, C. Zhao, S. Kawano, P. A. Beachy, Spatially restricted Hedgehog signalling regulates HGF-induced branching of the adult prostate. Nat. Cell Biol. 16, 1135-1145 (2014). doi: 10.1038/ncb3057; pmid: 25362352

4. M. T. Lewis et al., The Gli2 transcription factor is required for normal mouse mammary gland development. Dev. Biol. 238 133-144 (2001). doi: 10.1006/dbio.2001.0410; pmid: 11783999

5. A. Pertzelan, L. Yalon, R. Kauli, Z. Laron, A comparative study of the effect of oestrogen substitution therapy on breast development in girls with hypo- and hypergonadotrophic hypogonadism. Clin. Endocrinol. (Oxf.) 16, 359-368 (1982). pmid: 6980064

6. M. M. França et al., Novel heterozygous nonsense GLI2 mutations in patients with hypopituitarism and ectopic posterior pituitary lobe without holoprosencephaly. J. Clin. Endocrinol. Metab. 95, E384-E391 (2010). doi: 10.1210/ jc.2010-1050; pmid: 20685856

7. M. M. França et al., Relatively high frequency of nonsynonymous GLI2 variants in patients with congenital hypopituitarism without holoprosencephaly. Clin. Endocrinol. (Oxf) 78, 551-557 (2013). pmid: 22967285

8. E. Roessler et al., A previously unidentified amino-terminal domain regulates transcriptional activity of wild-type and disease-associated human GLI2. Hum. Mol. Genet. 14 2181-2188 (2005). doi: 10.1093/hmg/ddi222; pmid: 15994174

9. M. Y. Lee, L. Sun, J. M. Veltmaat, Hedgehog and Gli signaling in embryonic mammary gland development. J. Mammary Gland Biol. Neoplasia 18, 133-138 (2013). doi: 10.1007/s10911-0139291-7; pmid: 23677624

10. J. M. Veltmaat et al., Gli3-mediated somitic Fgf10 expression gradients are required for the induction and patterning of mammary epithelium along the embryonic axes. Development 133, 2325-2335 (2006). doi: 10.1242/dev.02394; pmid: 16720875

11. M. Y. Lee et al., Ectodermal influx and cell hypertrophy provide early growth for all murine mammary rudiments, and are differentially regulated among them by Gli3. PLOS ONE 6, e26242 (2011). doi: 10.1371/journal. pone.0026242; pmid: 22046263

12. S. J. Hatsell, P. Cowin, Gli3-mediated repression of Hedgehog targets is required for normal mammary development. Development 133, 3661-3670 (2006). doi: 10.1242/dev.02542; pmid: 16914490

13. N. J. Kenney, G. H. Smith, E. Lawrence, J. C. Barrett, D. S. Salomon, Identification of stem cell units in the terminal end bud and duct of the mouse mammary gland. J. Biomed. Biotechnol. 1, 133-143 (2001). doi: 10.1155/ S1110724301000304; pmid: 12488607

14. L. Bai, L. R. Rohrschneider, s-SHIP promoter expression marks activated stem cells in developing mouse mammary tissue. Genes Dev. 24, 1882-1892 (2010). doi: 10.1101/gad.1932810 pmid: 20810647

15. B. E. Welm et al., Sca-1(pos) cells in the mouse mammary gland represent an enriched progenitor cell population. De Biol. 245, 42-56 (2002). doi: 10.1006/dbio.2002.0625; pmid: 11969254

16. G. H. Smith, D. Medina, Re-evaluation of mammary stem cell biology based on in vivo transplantation. BCR 10, 203 (2008). doi: 10.1186/bcr1856; pmid: 18304381

17. J. E. Visvader, G. H. Smith, Murine mammary epithelial stem cells: Discovery, function, and current status. Cold Spring Harb. Perspect. Biol. 3, a004879 (2011). doi: 10.1101/cshperspect. a004879; pmid: 20926515

18. J. E. Visvader, J. Stingl, Mammary stem cells and the differentiation hierarchy: Current status and perspectives. Genes Dev. 28, 1143-1158 (2014). doi: 10.1101/gad.242511.114; pmid: 24888586

19. H. Moses, M. H. Barcellos-Hoff, TGF-beta biology in mammary development and breast cancer. Cold Spring Harb. Perspect. Biol. 3, a003277 (2011). doi: 10.1101/cshperspect.a003277; pmid: 20810549

20. J. Mao et al., A novel somatic mouse model to survey tumorigenic potential applied to the Hedgehog pathway. Cancer Res. 66, 10171-10178 (2006). doi: 10.1158/0008-5472. CAN-06-0657; pmid: 17047082

21. J. Taipale et al., Effects of oncogenic mutations in Smoothened and Patched can be reversed by cyclopamine. Nature 406, 1005-1009 (2000). doi: 10.1038/35023008; pmid: 10984056

22. M. Shackleton et al., Generation of a functional mammary gland from a single stem cell. Nature 439, 84-88 (2006) doi: 10.1038/nature04372; pmid: 16397499

23. J. Stingl et al., Purification and unique properties of mammary epithelial stem cells. Nature 439, 993-997 (2006). pmid: 16395311
24. C. Brisken, S. Duss, Stem cells and the stem cell niche in the breast: An integrated hormonal and developmental perspective. Stem Cell Rev. 3, 147-156 (2007). doi: 10.1007/ s12015-007-0019-1; pmid: 17873347

25. M. D. Sternlicht, Key stages in mammary gland development: The cues that regulate ductal branching morphogenesis. BCR 8, 201 (2006). doi: 10.1186/bcr1368 pmid: 16524451

26. V. Gouon-Evans, M. E. Rothenberg, J. W. Pollard, Postnatal mammary gland development requires macrophages and eosinophils. Development 127, 2269-2282 (2000). pmid: 10804170

27. G. A. Wood, J. E. Fata, K. L. Watson, R. Khokha, Circulating hormones and estrous stage predict cellular and stromal remodeling in murine uterus. Reproduction 133 1035-1044 (2007). doi: 10.1530/REP-06-0302; pmid: 17616732

28. N. M. Badders et al., The Wnt receptor, Lrp5, is expressed by mouse mammary stem cells and is required to maintain the basal lineage. PLOS ONE 4, e6594 (2009). doi: 10.1371/journal. pone.0006594; pmid: 19672307

29. Y. A. Zeng, R. Nusse, Wnt proteins are self-renewal factors for mammary stem cells and promote their long-term expansion in culture. Cell Stem Cell 6, 568-577 (2010) doi: 10.1016/i.stem.2010.03.020; pmid: 20569694

30. W. Ruan, D. L. Kleinberg, Insulin-like growth factor I is essential for terminal end bud formation and ductal morphogenesis during mammary development. Endocrinology 140, 5075-5081 (1999). pmid: 10537134

31. S. G. Bonnette, D. L. Hadsell, Targeted disruption of the IGF-I receptor gene decreases cellular proliferation in mammary terminal end buds. Endocrinology 142, 4937-4945 (2001). doi: 10.1210/endo.142.11.8500; pmid: 11606462

32. M. L. Asselin-Labat et al., Control of mammary stem cell function by steroid hormone signalling Nature 465, 798-802 (2010). doi: 10.1038/nature09027; pmid: 20383121

33. P. A. Joshi et al., Progesterone induces adult mammary stem cell expansion. Nature 465, 803-807 (2010). doi: 10.1038/ nature09091; pmid: 20445538

34. M. L. Asselin-Labat et al., Steroid hormone receptor status of mouse mammary stem cells. J. Natl. Cancer Inst. 98 1011-1014 (2006). doi: 10.1093/jnci/dji267; pmid: 16849684

35. F. Darendeliler, A. Lindberg, P. Wilton, Response to growth hormone treatment in isolated growth hormone deficiency versus multiple pituitary hormone deficiency. Horm. Res. Paediatr. 76 (suppl. 1), 42-46 (2011). doi: 10.1159/000329161: pmid: 21778748

36. M. Maghnie et al., Adult height in patients with permanent growth hormone deficiency with and without multiple pituitary hormone deficiencies. J. Clin. Endocrinol. Metab. 91, 2900-2905 (2006). doi: 10.1210/jc.2006-0050; pmid: 16684828

37. S. J. Morrison, D. T. Scadden, The bone marrow niche for haematopoietic stem cells. Nature 505, 327-334 (2014). doi: 10.1038/nature12984; pmid: 24429631

38. C. B. Bai, A. L. Joyner, Gli1 can rescue the in vivo function of Gli2. Development 128, 5161-5172 (2001). pmid: 11748151

39. J. D. Corrales, S. Blaess, E. M. Mahoney, A. L. Joyner, The level of sonic hedgehog signaling regulates the complexity of cerebellar foliation. Development 133, 1811-1821 (2006). doi: 10.1242/dev.02351; pmid: 16571625

40. M. D. Muzumdar, B. Tasic, K. Miyamichi, L. Li, L. Luo, A global double-fluorescent Cre reporter mouse. Genesis 45, 593-605 (2007). doi: 10.1002/dvg.20335; pmid: 17868096

41. F. Strutz et al., Identification and characterization of a fibroblast marker: FSP1. J. Cell Biol. 130, 393-405 (1995). doi: 10.1083/jcb.130.2.393; pmid: 7615639

42. G. Y. Lee, P. A. Kenny, E. H. Lee, M. J. Bissell, Threedimensional culture models of normal and malignant breast epithelial cells. Nat. Methods 4, 359-365 (2007). doi: 10.1038/ nmeth1015; pmid: 17396127

43. J. L. Whyte et al., Augmenting endogenous Wnt signaling improves skin wound healing. PLOS ONE 8 e76883 (2013). doi: 10.1371/journal.pone.0076883 pmid: 24204695

44. C. R. Taylor et al., Comparative study of antigen retrieval heating methods: Microwave, microwave and pressure cooker, autoclave, and steamer. Biotech. Histochem. 71, 263-270 (1996). doi: 10.3109/10520299609117171; pmid: 8896801 
45. M. Diehn et al., Association of reactive oxygen species levels and radioresistance in cancer stem cells. Nature 458, 780-783 (2009). doi: 10.1038/nature07733; pmid: 19194462

46. P. Dalerba et al., Single-cell dissection of transcriptional heterogeneity in human colon tumors. Nat. Biotechnol. 29, 1120-1127 (2011). doi: 10.1038/nbt.2038; pmid: 22081019

47. S. D. Robinson, G. B. Silberstein, A. B. Roberts, K. C. Flanders, C. W. Daniel, Regulated expression and growth inhibitory effects of transforming growth factor-beta isoforms in mouse mammary gland development. Development 113, 867-878 (1991). pmid: 1821856

48. W. Ruan, C. B. Newman, D. L. Kleinberg, Intact and aminoterminally shortened forms of insulin-like growth factor I induce mammary gland differentiation and development. Proc. Natl. Acad. Sci. U.S.A. 89, 10872-10876 (1992). doi: 10.1073/ pnas.89.22.10872; pmid: 1438291

49. W. Ruan, V. Catanese, R. Wieczorek, M. Feldman, D. L. Kleinberg, Estradiol enhances the stimulatory effect of insulin-like growth factor-I (IGF-I) on mammary development and growth hormone-induced IGF-I messenger ribonucleic acid. Endocrinology 136 1296-1302 (1995). pmid: 7867584

50. M. J. Guerquin et al., Transcription factor EGR1 directs tendon differentiation and promotes tendon repair. J. Clin. Invest. 123, 3564-3576 (2013). doi: 10.1172/ JCI67521; pmid: 23863709

51. E. D. Cohen et al., Wnt signaling regulates smooth muscle precursor development in the mouse lung via a tenascin C/PDGFR pathway. J. Clin. Invest. 119, 2538-2549 (2009). doi: 10.1172/JCI38079; pmid: 19690384

52. M. Kundakovic et al., Sex-specific epigenetic disruption and behavioral changes following low-dose in utero bisphenol A exposure. Proc. Natl. Acad. Sci. U.S.A. 110, 9956-9961 (2013). doi: 10.1073/pnas.1214056110; pmid: 23716699

\section{ACKNOWLEDGMENTS}

This work was supported by a Susan G. Komen fellowship to C.Z. and funding from the U.S. Department of Defense, the Breast Cancer Research Foundation, and the Ludwig Institute for Cancer Research. The cell imaging core of Stanford Neuroscience Microscopy Service and the FACS core of Stanford Institute for Stem Cell Biology and Regenerative Medicine were supported by $\mathrm{NIH}$ core grants. We are grateful to K. M. Loh and J. Sage for critical reading and helpful discussion of this manuscript. P.A.B. is an investigator of the Howard Hughes Medical Institute.

\section{SUPPLEMENTARY MATERIALS}

www.sciencemag.org/content/356/6335/eaal3485/suppl/DC1 Figs. S1 to S10

5 November 2016; accepted 1 March 2017

Published online 9 March 2017

10.1126/science.aal3485 


\section{Science}

\section{Stromal Gli2 activity coordinates a niche signaling program for mammary epithelial stem cells}

Chen Zhao, Shang Cai, Kunyoo Shin, Agnes Lim, Tomer Kalisky, Wan-Jin Lu, Michael F. Clarke and Philip A. Beachy

Science 356 (6335), eaal3485.

DOI: 10.1126/science.aal3485originally published online March 9, 2017

\section{Double duty for mammary stem cell niche}

The stem cell niche is a complex local signaling microenvironment that regulates stem cell activity for tissue and organ maintenance and regeneration. As well as responding locally, during puberty, the mammary gland stem cell niche also responds to systemic hormonal signals. Zhao et al. have found that Gli2, a transcriptional effector of Hedgehog signaling, coordinates the niche-signaling program and activates expression of receptors for the mammatrophic hormones estrogen and growth hormone throughout the mammary gland (see the Perspective by Robertson). Disease may result not only from stem cell defects, but also from dysregulation of the microenvironment.

Science, this issue p. eaal3485; see also p. 250

ARTICLE TOOLS

SUPPLEMENTARY MATERIALS

RELATED

CONTENT

REFERENCES

PERMISSIONS http://science.sciencemag.org/content/356/6335/eaal3485

http://science.sciencemag.org/content/suppl/2017/03/08/science.aal3485.DC1

http://science.sciencemag.org/content/sci/356/6335/250.full http://stm.sciencemag.org/content/scitransmed/7/301/301 ra130.full

http://stm.sciencemag.org/content/scitransmed/2/31/31ps22.full

http://stke.sciencemag.org/content/sigtrans/8/394/ra92.full

http://stke.sciencemag.org/content/sigtrans/8/401/pe3.full

http://stke.sciencemag.org/content/sigtrans/10/467/eaah4674.full

This article cites 52 articles, 15 of which you can access for free http://science.sciencemag.org/content/356/6335/eaal3485\#BIBL

http://www.sciencemag.org/help/reprints-and-permissions

Use of this article is subject to the Terms of Service

Science (print ISSN 0036-8075; online ISSN 1095-9203) is published by the American Association for the Advancement of Science, 1200 New York Avenue NW, Washington, DC 20005. 2017 () The Authors, some rights reserved; exclusive licensee American Association for the Advancement of Science. No claim to original U.S. Government Works. The title Science is a registered trademark of AAAS. 